\title{
The ability of CMIP5 models to simulate North Atlantic extratropical cyclones
}

\section{Article}

Published Version

Zappa, G., Shaffrey, L. C. and Hodges, K. I. (2013) The ability of CMIP5 models to simulate North Atlantic extratropical cyclones. Journal of Climate, 26 (15). pp. 5379-5396. ISSN 1520-0442 doi: https://doi.org/10.1175/JCLI-D-12-00501.1 Available at https://centaur.reading.ac.uk/34544/

It is advisable to refer to the publisher's version if you intend to cite from the work. See Guidance on citing.

To link to this article DOI: http://dx.doi.org/10.1175/JCLI-D-12-00501.1

Publisher: American Meteorological Society

All outputs in CentAUR are protected by Intellectual Property Rights law, including copyright law. Copyright and IPR is retained by the creators or other copyright holders. Terms and conditions for use of this material are defined in the End User Agreement.

\section{www.reading.ac.uk/centaur}

\section{CentAUR}

Central Archive at the University of Reading

Reading's research outputs online 


\title{
The Ability of CMIP5 Models to Simulate North Atlantic Extratropical Cyclones*
}

\author{
GIUSEPPE ZAPPA AND LEN C. SHAFFREY \\ Department of Meteorology, and National Centre for Atmospheric Science, University of Reading, Reading, United Kingdom
}

KEVIN I. HoDGES

National Centre for Earth Observation, University of Reading, Reading, United Kingdom

(Manuscript received 18 July 2012, in final form 27 December 2012)

\begin{abstract}
The ability of the climate models participating in phase 5 of the Coupled Model Intercomparison Project (CMIP5) to simulate North Atlantic extratropical cyclones in winter [December-February (DJF)] and summer [June-August (JJA)] is investigated in detail. Cyclones are identified as maxima in T42 vorticity at $850 \mathrm{hPa}$ and their propagation is tracked using an objective feature-tracking algorithm. By comparing the historical CMIP5 simulations (1976-2005) and the ECMWF Interim Re-Analysis (ERA-Interim; 1979-2008), the authors find that systematic biases affect the number and intensity of North Atlantic cyclones in CMIP5 models. In DJF, the North Atlantic storm track tends to be either too zonal or displaced southward, thus leading to too few and weak cyclones over the Norwegian Sea and too many cyclones in central Europe. In JJA, the position of the North Atlantic storm track is generally well captured but some CMIP5 models underestimate the total number of cyclones. The dynamical intensity of cyclones, as measured by either T42 vorticity at $850 \mathrm{hPa}$ or mean sea level pressure, is too weak in both DJF and JJA. The intensity bias has a hemispheric character, and it cannot be simply attributed to the representation of the North Atlantic largescale atmospheric state. Despite these biases, the representation of Northern Hemisphere (NH) storm tracks has improved since CMIP3 and some CMIP5 models are able of representing well both the number and the intensity of North Atlantic cyclones. In particular, some of the higher-atmospheric-resolution models tend to have a better representation of the tilt of the North Atlantic storm track and of the intensity of cyclones in DJF.
\end{abstract}

\section{Introduction}

Extratropical cyclones are the main driver of the dayto-day midlatitude weather variability. A large fraction of the meridional transport of heat, momentum, and moisture in midlatitudes is carried by extratropical cyclones (Peixoto and Oort 1992), which makes them fundamental in determining the equilibrium state of the climate system. Extratropical cyclones also have large socioeconomic impacts. In particular, wintertime precipitation over midlatitude land is generally associated with

\footnotetext{
* Supplemental information related to this paper is available at the Journals Online website: http://dx.doi.org/10.1175/ JCLI-D-12-00501.s1.

Corresponding author address: Giuseppe Zappa, Department of Meteorology, University of Reading, Earley Gate, P.O. Box 243, Reading RG6 6BP, United Kingdom.

E-mail: g.zappa@reading.ac.uk
}

extratropical cyclones, which are important in providing the available freshwater for agricultural and societal needs. Landfalling cyclones of extreme intensity can generate highly damaging windstorms or intense precipitation events leading to potentially large socioeconomic losses (Lamb 1991; Fink et al. 2009).

Any future changes in extratropical cyclones will have large socioeconomic impacts. For instance, a future increase in European windstorm risk (Leckebusch and Ulbrich 2004; Pinto et al. 2007a) might result because of an intensification of North Atlantic cyclone activity in response to increasing greenhouse gases (Bengtsson et al. 2006; Ulbrich et al. 2008, 2009). Evaluating the ability of climate models to adequately represent the dynamics of extratropical cyclones is essential for increasing the confidence in the future projections.

Insight into the spatial distribution and the intensities of extratropical cyclones can be gained by the objective identification and tracking of cyclones. A variety of cyclone tracking algorithms have been developed and 
applied to the study of extratropical storm tracks in observational reanalysis datasets (Wang et al. 2006; Raible et al. 2008; Hodges et al. 2011) and in climate model simulations of present and future climates (Sinclair and Watterson 1999; Leckebusch and Ulbrich 2004; Bengtsson et al. 2006; Greeves et al. 2007; Pinto et al. 2007b; Bengtsson et al. 2009; Catto et al. 2011). However, some of the studies that have analyzed the future changes in extratropical cyclones have only briefly discussed the model biases in cyclone behavior. Furthermore, the use of different tracking algorithms and tracked fields in different climate models may highlight different aspects of extratropical cyclone activity (Raible et al. 2008; Neu et al. 2012). This limits the possibility of obtaining a comprehensive and self-consistent view of the systematic biases affecting climate models. Therefore, a multimodel assessment of extratropical cyclones using a common tracking technique is needed to quantify the magnitude and the intermodel spread of climate model biases and to determine whether the biases might have impacts on the future projections (e.g., Kidston and Gerber 2010).

A series of globally coordinated climate model experiments, of which the Coupled Model Intercomparison Project (CMIP) is an important part, have been promoted by the World Climate Research Program (WCRP) to analyze global climate models (GCMs) in a systematic fashion and facilitate their improvement by identifying common deficiencies. However, because of the limited data availability of previous CMIPs-ideally 6-hourly model output data are required for tracking cyclones (e.g., Blender and Schubert 2000)—multimodel assessments of extratropical storm tracks have either employed simple cyclone identification techniques (Lambert et al. 2002; Lambert and Fyfe 2006) or have analyzed the Eulerian (Ulbrich et al. 2008) or spectral (Lucarini et al. 2007) variance of atmospheric synoptic waves. Recognizing the importance of evaluating extremes in present and future climates, the WCRP included high-frequency (6 hourly) model output data in the standard diagnostics of phase 5 of CMIP (CMIP5). This makes cyclone tracking a viable opportunity for assessing a wide range of climate models for the first time.

The aim of this study is to provide a detailed evaluation of the ability of CMIP5 models to simulate North Atlantic cyclones. The use of a tracking algorithm allows us to separately analyze the number, the intensity, and the spatial distribution of North Atlantic cyclones. This approach also allows us to explore whether the number of cyclones of extreme intensity is adequately captured. Both the winter [December-February (DJF)] season and the summer [June-August (JJA)] season, which has been given little attention in previous studies, are investigated. The biases of the models are estimated by comparing the cyclone statistics with observational reanalyses datasets. The future response of the North Atlantic cyclones to climate change is instead presented in Zappa et al. (2013).

The structure of the paper is as follows: In section 2, we describe the tracking algorithm and the datasets. In section 3, we present the bias and the spread in the spatial distribution of North Atlantic cyclones in the CMIP5 models. In section 4, the performance of the CMIP5 models is quantified by introducing metrics of the intensity and number of North Atlantic cyclones. A discussion of the biases of the models and of their relation with the large-scale atmospheric and oceanic state is presented in section 5, and a summary of the paper and its conclusions are finally given in section 6 .

\section{Data and methods}

\section{a. Cyclone tracking and Eulerian statistics}

The cyclone tracking is based on Hodges (1994, 1995, 1999) objective feature-tracking algorithm. This method has been widely used in previous studies for analyzing both the basic dynamics of extratropical storm tracks (Hoskins and Hodges 2002), the performance of climate models in capturing the location and structure of extratropical cyclones (Greeves et al. 2007; Bengtsson et al. 2009; Catto et al. 2010), and the future response to climate change (Bengtsson et al. 2006, 2009; Catto et al. 2011). The main characteristics of the tracking algorithm are as follows: The 6-hourly vorticity at $850 \mathrm{hPa}$ is computed from the zonal and meridional wind speeds. The vorticity is then spectrally smoothed to a common T42 grid. The background vorticity field, which is defined by the spherical harmonics of total wavenumber smaller than 6 , is removed. Cyclones are then identified as the relative maxima in the T42 vorticity at $850 \mathrm{hPa}$ that exceed an intensity of $10^{-5} \mathrm{~s}^{-1}$. The tracks of the cyclones are determined by minimizing a cost function in the track smoothness subject to constraints on displacement and track smoothness. Further kinematic thresholds-minimum lifetime (2 days) and minimum propagation $(1000 \mathrm{~km})$ - are finally applied to select the tracks that are consistent with the propagating nature of extratropical cyclones and to exclude unrealistic shortlived or stationary features. The main conclusions of the paper proved to be robust with respect to halving the kinematic thresholds to 1 -day lifetime and $500-\mathrm{km}$ displacement. Similar sensitivity studies are also presented in Jung et al. (2012).

Tracking $850-\mathrm{hPa}$ vorticity at T42 guarantees that the focus will be on features of similar spatial scale across models of different atmospheric resolution (Blender 
and Schubert 2000). The intensity of cyclones will be evaluated by the same quantity adopted for the tracking (i.e., $850-\mathrm{hPa}$ vorticity at $\mathrm{T} 42$ resolution). This metric quantifies the cyclonic intensity of the circulation, it is not explicitly dependent on the model horizontal resolution, and it is only weakly affected by the large-scale atmospheric state. The impact of considering different metrics of cyclone intensity, such as the minimum mean sea level pressure (MSLP) and the maximum wind speed at $850 \mathrm{hPa}$ searched in a $5^{\circ}$ and $6^{\circ}$ spherical cap around the vorticity maxima, respectively, has also been tested and will be briefly discussed in section 4 . The spatial maps of the number of cyclones month ${ }^{-1}$ (unit area) ${ }^{-1}$ (i.e., the track density) and of the mean intensity of cyclones are computed by the spherical kernel estimators described in Hodges (1996).

Analyzing the variance of synoptic fluctuations of atmospheric variables is a standard approach to quantifying extratropical storm-track activity (Blackmon 1976; Wallace et al. 1988; Chang 2009). Although synoptic variance statistics convolve both the number and the intensity of cyclones and, to a lesser extent, of anticyclones, they have the advantage of being less dependent on the specific formulation than a tracking algorithm (Chang 2009). Therefore, we will consider the 2-6-day bandpass filter standard deviation (std dev) of MSLP to complement the storm-tracking results and also to investigate the improvements of CMIP5 models with respect to the climate models that participated in phase 3 of CMIP (CMIP3). MSLP is here chosen because available at daily frequency in both CMIP3 and CMIP5 models. The variance is obtained by filtering the daily data with a 61-point Lanczos filter (Duchon 1979).

\section{b. CMIP5 models}

In this paper, we will consider the present-day historical and Atmospheric Model Intercomparison Project (AMIP)-style simulations performed by the 22 CMIP5 climate models listed in Table 1. For each model, the climate statistics are averaged across all the available ensembles to reduce the uncertainty due to sampling. The term "historical" (HIST) refers to coupled climate model simulations forced by observed concentrations of greenhouse gases, solar forcing, aerosols, ozone, and land-use change over the 1850-2005 period (Taylor et al. 2012). The last $30 \mathrm{yr}(1976-2005)$ are analyzed to compare CMIP5 models with the observational reanalysis datasets. The AMIP simulations are atmosphere-only runs forced by the observed monthly sea surface temperatures (SSTs) and sea ice concentrations over the time period $1980-2008$.

The dynamical core of the atmospheric component of the model is likely to play a major role in determining the extratropical cyclones behavior. Models with both spectral and gridpoint dynamical core are participating in CMIP5. The resolution of the gridpoint models range from grid points of $96 \times 96(\sim 310 \mathrm{~km})$ to $288 \times 192(\sim 120 \mathrm{~km})$. Spectral models have horizontal atmospheric resolution ranging from T42 (Gaussian grid resolution of $\sim 310 \mathrm{~km}$ ) to T159 $(\sim 80 \mathrm{~km})$. The CMIP5 models also have a range of different vertical resolutions, ranging from about 20 to 80 levels, with about the half of the CMIP5 models also featuring a well-resolved stratosphere (model top above $1 \mathrm{hPa}$ ).

\section{c. Observational reanalyses datasets}

Reanalysis datasets are commonly adopted for evaluating climate models. Hodges et al. (2011) analyzed the statistics of extratropical cyclones tracked in four modern reanalyses: the European Centre for MediumRange Weather Forecasts (ECMWF) Interim Re-Analysis (ERA-Interim; Simmons et al. 2007), the Japanese 25-yr Reanalysis (JRA-25; Onogi et al. 2007), the National Centers for Environmental Prediction Climate Forecast System Reanalysis (NCEP CFSR; Saha et al. 2010), and National Aeronautics and Space Administration Modern Era Retrospective-Analysis for Research and Applications (NASA MERRA; Rienecker et al. 2011). They found the four reanalyses show a very similar spatial distribution of North Atlantic cyclones and a good one-to-one cyclone correspondence over the Northern Hemisphere. Subsequently, ERA-Interim will here be used to evaluate the spatial distribution of cyclones of CMIP5 models. However, only partial agreement was found by Hodges et al. (2011) in the intensity of cyclones of the four reanalyses, with NASA MERRA showing larger DJF cyclone intensities as measured by either wind speed maxima or MSLP minima. To take into account such observational uncertainty, the spread of cyclone intensities in CMIP5 models will be compared against the spread of the four reanalyses (see Table 2). The reanalyses are analyzed for the 1980-2009 period. The slight differences with the temporal period analyzed in the CMIP5 AMIP and HIST simulations are due to the unavailability of data on a common 30-yr period and have a negligible impact on the assessment of the model biases.

\section{Spatial distribution of cyclones}

\section{a. ERA-Interim}

Figure 1 shows the 2-6-day MSLP std dev, the track density, and the mean cyclone intensity from ERAInterim in DJF and JJA.

In DJF, the North Atlantic storm track features a large meridional tilt, which is clear in all the three 
TABLE 1. List of CMIP5 models including the horizontal and vertical resolution of the atmospheric component of the model and the number of analyzed ensembles for the historical and the AMIP simulations. The resolution of spectral models is indicated by the truncation type, followed by the truncation number and the dimension of the output Gaussian grid (in parenthesis). Here, " $T$ " stands for triangular truncation, "TL" stands for triangular truncation with linear Gaussian grid, and " $\mathrm{R}$ " stands for rhomboidal truncation. The resolution of gridpoint models is given by the dimension of the grid. The term "C48" refers to a cubed-sphere finite volumes model, and the average size of its grids is indicated in kilometers. The labels are used to identify the CMIP5 models in Figs. 4, 7, and 10.

\begin{tabular}{|c|c|c|c|c|c|c|c|}
\hline \multirow[b]{2}{*}{ Label } & \multicolumn{3}{|c|}{ Basic information } & \multicolumn{2}{|c|}{$\begin{array}{l}\text { Atmospheric } \\
\text { resolution }\end{array}$} & \multicolumn{2}{|c|}{$\begin{array}{c}\text { No. of } \\
\text { ensembles }\end{array}$} \\
\hline & Model name & Model expansion & Institution & Horizontal & Vertical & HIST & AMIP \\
\hline 1 & BCC-CSM1.1 & $\begin{array}{l}\text { Beijing Climate Center } \\
\text { (BCC), Climate System } \\
\text { Model, version } 1.1\end{array}$ & BCC, China & T42 $(128 \times 64)$ & 26 & 3 & 3 \\
\hline 2 & BCC-CSM1.1m & $\begin{array}{l}\text { BCC, Climate System } \\
\text { Model, version } 1.1 \mathrm{~m}\end{array}$ & & T106 $(320 \times 160)$ & 26 & 1 & 2 \\
\hline 3 & CanESM2 & $\begin{array}{l}\text { Second Generation } \\
\text { Canadian Earth System } \\
\text { Model }\end{array}$ & $\begin{array}{l}\text { Canadian Centre for } \\
\text { Climate Modelling and } \\
\text { Analysis (CCCma), } \\
\text { Canada }\end{array}$ & T63 $(128 \times 64)$ & 35 & 5 & 3 \\
\hline 4 & CCSM4 & $\begin{array}{l}\text { Community Climate } \\
\text { System Model (CCSM), } \\
\text { version } 4\end{array}$ & $\begin{array}{l}\text { National Center for } \\
\text { Atmospheric Research } \\
\text { (NCAR), United States }\end{array}$ & $280 \times 200$ & 27 & 1 & 1 \\
\hline 5 & CMCC-CM & $\begin{array}{l}\text { Centro Euro-Mediterraneo } \\
\text { per i Cambiamenti } \\
\text { Climatici (CMCC) } \\
\text { Climate Model }\end{array}$ & CMCC, Italy & $\mathrm{T} 159(480 \times 240)$ & 31 & 1 & 0 \\
\hline 6 & CNRM-CM5 & $\begin{array}{l}\text { Centre National de } \\
\text { Recherches } \\
\text { Météorologiques } \\
\text { (CNRM) Coupled } \\
\text { Global Climate Model, } \\
\text { version } 5\end{array}$ & $\begin{array}{l}\text { CNRM-Centre Européen } \\
\text { de Recherche et de } \\
\text { Formation Avancée en } \\
\text { Calcul Scientifique } \\
\text { (CERFACS), France }\end{array}$ & TL127 $(256 \times 128)$ & 31 & 5 & 1 \\
\hline 7 & CSIRO Mk3.6.0 & $\begin{array}{l}\text { Commonwealth Scientific } \\
\text { and Industrial Research } \\
\text { Organisation (CSIRO) } \\
\text { Mark, version 3.6.0 }\end{array}$ & $\begin{array}{l}\text { CSIRO Queensland } \\
\text { Climate Change Centre } \\
\text { of Excellence (QCCCE), } \\
\text { Australia }\end{array}$ & T63 $(192 \times 96)$ & 18 & 4 & 5 \\
\hline 8 & EC-Earth & EC-Earth consortium & $\begin{array}{l}\text { Swedish Meteorological } \\
\text { and Hydrological } \\
\text { Institute (SMHI)/ } \\
\text { Stockholm University, } \\
\text { Meteorologiska } \\
\text { Institutionen (MISU), } \\
\text { Sweden }\end{array}$ & TL159 $(320 \times 160)$ & 62 & 3 & 0 \\
\hline 9 & FGOALS-g2 & $\begin{array}{l}\text { Flexible Global Ocean- } \\
\text { Atmosphere-Land } \\
\text { System Model gridpoint, } \\
\text { version } 2\end{array}$ & $\begin{array}{l}\text { State Key Laboratory of } \\
\text { Numerical Modeling for } \\
\text { Atmospheric Sciences } \\
\text { and Geophysical Fluid }\end{array}$ & $128 \times 60$ & 26 & 1 & 1 \\
\hline 10 & FGOALS-s2 & $\begin{array}{l}\text { Flexible Global Ocean- } \\
\text { Atmosphere-Land } \\
\text { System Model gridpoint, } \\
\text { second spectral version }\end{array}$ & $\begin{array}{l}\text { Dynamics (LASG), } \\
\text { China }\end{array}$ & R42 $(128 \times 108)$ & 26 & 3 & 1 \\
\hline 11 & GFDL-ESM2M & $\begin{array}{l}\text { Geophysical Fluid } \\
\text { Dynamics Laboratory } \\
\text { (GFDL) Earth System } \\
\text { Model with MOM4 } \\
\text { ocean component } \\
\text { (ESM2M) }\end{array}$ & GFDL, United States & $144 \times 90$ & 24 & 1 & 0 \\
\hline 12 & GFDL CM3 & $\begin{array}{l}\text { GFDL Climate Model, } \\
\text { version } 3\end{array}$ & & $\mathrm{C} 48(\sim 200 \mathrm{~km})$ & 48 & 4 & 0 \\
\hline
\end{tabular}


TABLE 1. (Continued)

\begin{tabular}{|c|c|c|c|c|c|c|c|}
\hline \multirow[b]{2}{*}{ Label } & \multicolumn{3}{|c|}{ Basic information } & \multicolumn{2}{|c|}{$\begin{array}{l}\text { Atmospheric } \\
\text { resolution }\end{array}$} & \multicolumn{2}{|c|}{$\begin{array}{c}\text { No. of } \\
\text { ensembles }\end{array}$} \\
\hline & Model name & Model expansion & Institution & Horizontal & Vertical & HIST & AMIP \\
\hline 13 & HadGEM2-ES & $\begin{array}{l}\text { Hadley Centre Global } \\
\text { Environmental Model, } \\
\text { version } 2 \text { (Earth System) }\end{array}$ & $\begin{array}{l}\text { Met Office Hadley Centre, } \\
\text { United Kingdom }\end{array}$ & $192 \times 144$ & 38 & 1 & 1 \\
\hline 14 & INM-CM4 & $\begin{array}{l}\text { Institute of Numerical } \\
\text { Mathematics (INM) } \\
\text { Coupled Model, version } \\
4.0\end{array}$ & INM, Russia & $180 \times 120$ & 21 & 1 & 1 \\
\hline 15 & IPSL-CM5A-LR & $\begin{array}{l}\text { L'Institut Pierre-Simon } \\
\text { Laplace (IPSL) Coupled } \\
\text { Model, version 5, coupled } \\
\text { with the Nucleus for } \\
\text { European Modelling of } \\
\text { the Ocean (NEMO), low } \\
\text { resolution }\end{array}$ & IPSL, France & $96 \times 96$ & 39 & 4 & 5 \\
\hline 16 & IPSL-CM5A-MR & $\begin{array}{l}\text { IPSL Coupled Model, } \\
\text { version 5, coupled with } \\
\text { NEMO, mid resolution }\end{array}$ & & $144 \times 143$ & 39 & 1 & 0 \\
\hline 17 & IPSL-CM5B-LR & $\begin{array}{l}\text { IPSL Coupled Model, } \\
\text { version 5, coupled with } \\
\text { NEMO, low resolution }\end{array}$ & & $96 \times 96$ & 39 & 1 & 1 \\
\hline 18 & MPI-ESM-LR & $\begin{array}{l}\text { Max Planck Institute (MPI) } \\
\text { Earth System Model, low } \\
\text { resolution }\end{array}$ & MPI, Germany & T63 $(192 \times 96)$ & 47 & 3 & 3 \\
\hline 19 & MRI-CGCM3 & $\begin{array}{l}\text { Meteorological Research } \\
\text { Institute (MRI) Coupled } \\
\text { Atmosphere-Ocean } \\
\text { General Circulation } \\
\text { Model, version } 3\end{array}$ & MRI, Japan & TL159 $(320 \times 160)$ & 48 & 5 & 3 \\
\hline 20 & MIROC5 & $\begin{array}{l}\text { Model for Interdisciplinary } \\
\text { Research on Climate } \\
\text { (MIROC), version } 5\end{array}$ & MIROC, Japan & T85 $(256 \times 128)$ & 40 & 5 & 1 \\
\hline 21 & MIROC-ESM & $\begin{array}{l}\text { MIROC, Earth System } \\
\text { Model }\end{array}$ & & $\mathrm{T} 42(128 \times 64)$ & 80 & 3 & 0 \\
\hline 22 & NorESM1-M & $\begin{array}{l}\text { Norwegian Earth System } \\
\text { Model, version } 1 \\
\text { (medium resolution) }\end{array}$ & $\begin{array}{l}\text { Norwegian Climate Centre } \\
\text { (NCC), Norway }\end{array}$ & $144 \times 96$ & 26 & 3 & 3 \\
\hline
\end{tabular}

variables. For the track density, the maximum extends from about $45^{\circ} \mathrm{N}$ on the west Atlantic to about $70^{\circ} \mathrm{N}$ in the Norwegian Sea. The intensity of cyclones and the 2-6-day MSLP std dev both peak on the west Atlantic in the region of Newfoundland. This is consistent with the large meridional thermal gradient, which is a source of baroclinicity, between the cold North American continent and the warm Gulf Stream SSTs (Hoskins and Valdes 1990; Brayshaw et al. 2009).

By comparing DJF with JJA, we find that the North Atlantic storm track exhibits large seasonality. In JJA, the intensity of cyclones is weaker with respect to DJF,

TABLE 2. List of reanalysis datasets adopted for the evaluation of CMIP5 models: ERA-Interim, NCEP CFSR, NASA MERRA, and JRA-25. Labels are used in Fig. 7a.

\begin{tabular}{|c|c|c|c|c|}
\hline \multirow[b]{2}{*}{ Label } & \multicolumn{2}{|r|}{ Basic information } & \multicolumn{2}{|c|}{ Atmospheric resolution } \\
\hline & Reanalysis name & Institution & Horizontal & Vertical \\
\hline I & ERA-Interim & ECMWF, Europe & $\mathrm{T} 255$ & 80 \\
\hline $\mathrm{N}$ & NCEP CFSR & NCEP, United States & T382 & 64 \\
\hline M & NASA MERRA & NASA, United States & $540 \times 360$ & 72 \\
\hline $\mathrm{J}$ & JRA-25 & $\begin{array}{l}\text { Japan Meteorological Agency-Central Research Institute } \\
\text { of Electric Power Industry (JMA-CRIEPI), Japan }\end{array}$ & T106 & 40 \\
\hline
\end{tabular}



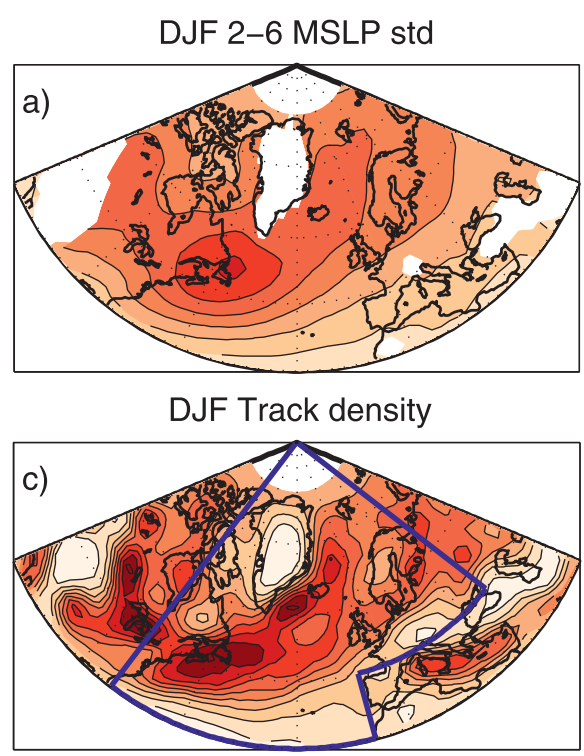

DJF Intensity

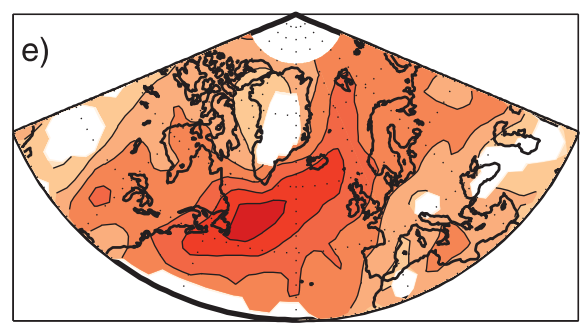

JJA 2-6 MSLP std

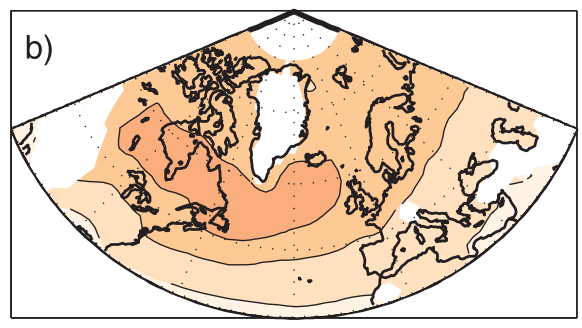

JJA Track density

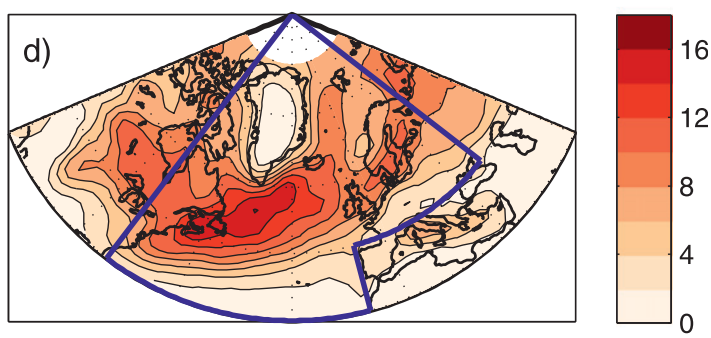

JJA Intensity

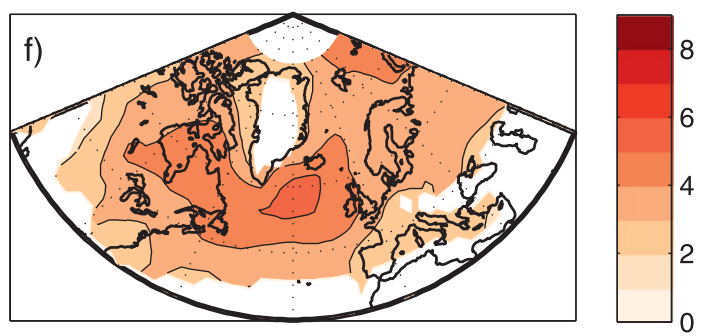

FIG. 1. (a),(b) The 2-6-day bandpass filtered std dev of MSLP $\left(10^{-1} \mathrm{hPa}\right)$; (c),(d) track density [cyclones month ${ }^{-1}$ $\left.\left(5^{\circ} \text { spherical cap }\right)^{-1}\right]$; and (e),(f) cyclone intensity $\left(10^{-5} \mathrm{~s}^{-1}\right)$ for ERA-Interim (1980-2009) for (left) DJF and (right) JJA. In (a),(b), the high orography is masked. The blue lines in (c) and (d) delimit the area where maximum alongtrack intensity has to occur for a cyclone to be defined as North Atlantic.

and the location of maximum intensity shifts to the central Atlantic $\left(\sim 30^{\circ} \mathrm{W}\right)$. Such changes are also seen in the 2-6-day MSLP std dev and are consistent with the reduced meridional temperature gradients. By comparing the track density in JJA with DJF, we also find a small reduction $(\sim 10 \%)$ in the number of North Atlantic cyclones and a large reduction $(\sim 50 \%)$ on the Norwegian Sea. This weaker cyclone activity on the Norwegian Sea in JJA is associated with the weaker tilt of the North Atlantic storm track compared with DJF. The ability of CMIP5 models to capture these features will be investigated in the next subsections.

\section{b. Eulerian CMIP3 versus CMIP5 comparison}

Many CMIP5 models follow from the development of models that previously participated in CMIP3. The improvements between the CMIP3 and the CMIP5 models involve increased model resolution, improved physical processes parameterizations, and increased model complexity. It is therefore of interest to determine whether such changes have led to an improved representation of extratropical storm tracks. The list of CMIP3 models here considered is given in the appendix.

Figure 2 shows the DJF and JJA multimodel mean bias of the CMIP3 and CMIP5 models relative to ERAInterim for 2-6-day MSLP std dev. This analysis is presented for the whole Northern Hemisphere (NH) so that the mean bias in the North Atlantic and Pacific storm tracks can be compared. In both DJF and JJA, the mean biases of the CMIP3 and CMIP5 models have a very similar spatial pattern. In DJF, the largest biases are found in the North Atlantic, where the 2-6-day MSLP std dev is too weak in the Arctic and in North America and too strong in a zonal band extending from the North Atlantic into central Europe. This is in agreement with the bias of CMIP3 models shown in Ulbrich et al. (2008) for DJF. However, the size of the mean bias of the CMIP5 models tends to be smaller than in the CMIP3 models. In particular, the largest improvement is found in the Atlantic sector of the Arctic Ocean (i.e., the 


\section{DJF CMIP3 bias}

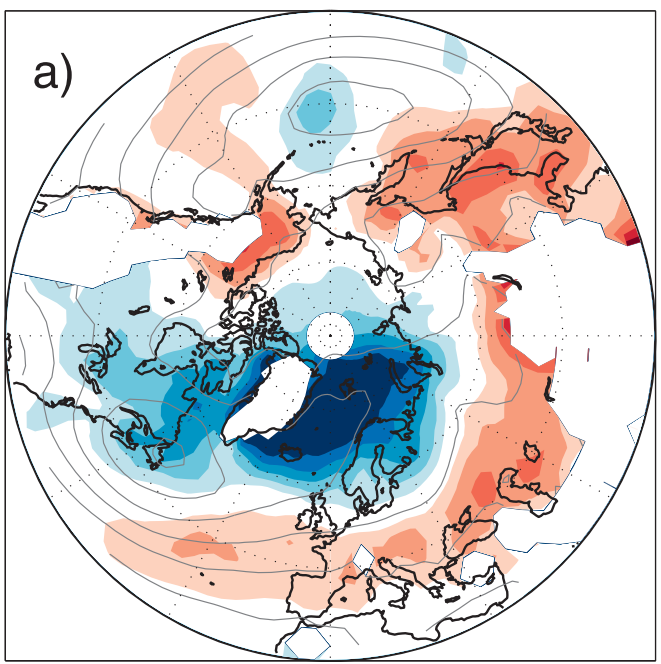

\section{DJF CMIP5 bias}

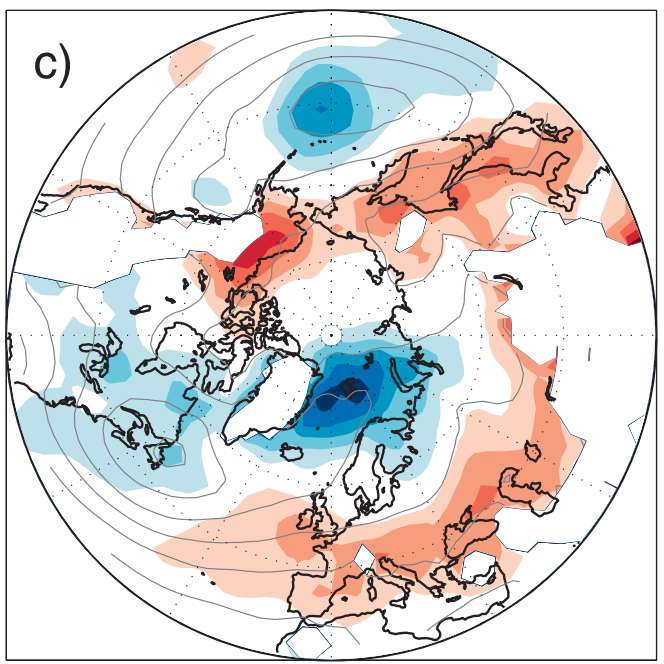

JJA CMIP3 bias

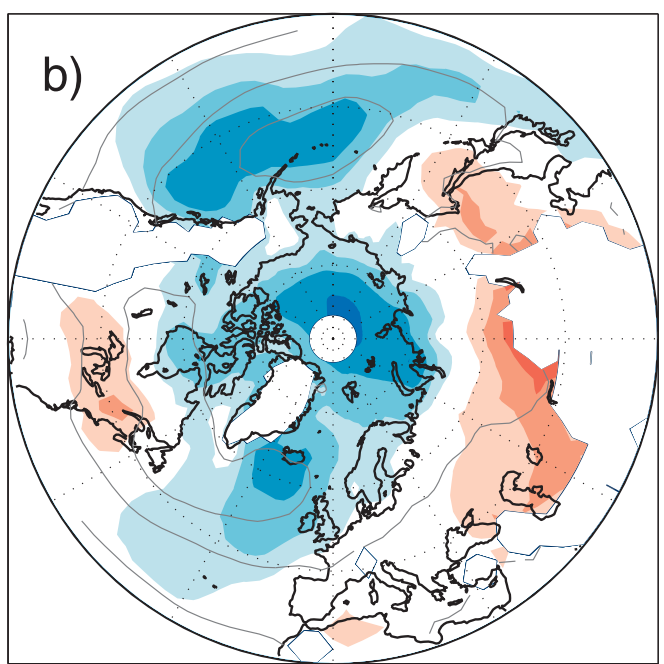

JJA CMIP5 bias

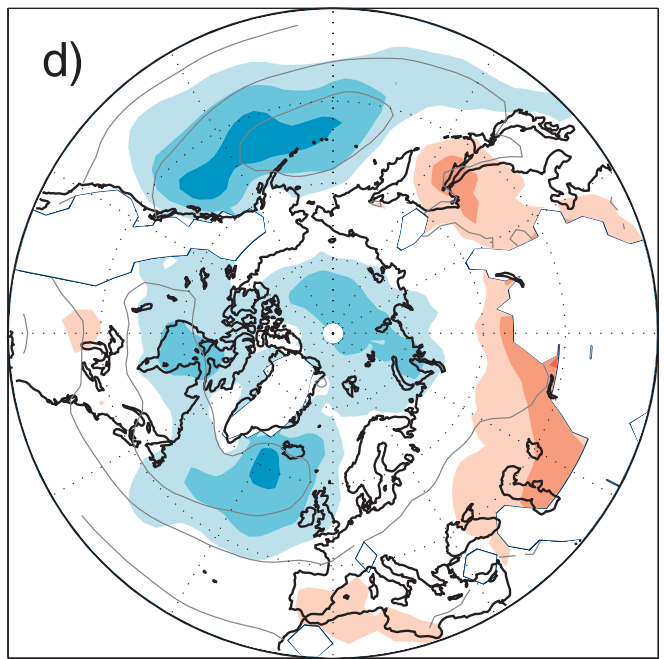

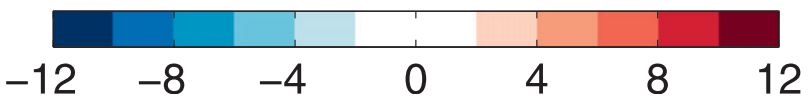

FIG. 2. Mean bias with respect to ERA-Interim (shading) in the 2-6-day MSLP std dev $\left(10^{-1} \mathrm{hPa}\right)$ of the control simulations of the (a),(b) CMIP3 and (c),(d) CMIP5 models for (left) DJF and (right) JJA. The ERA-Interim climatology is contoured with isolines every $1 \mathrm{hPa}$. High orography is masked.

Norwegian, Greenland, and Barents Seas area), where the bias of CMIP5 models is about halved with respect to CMIP3 models. This is indicative of an increased ability of CMIP5 models to capture the meridional tilt of the North Atlantic storm track. In JJA, the Pacific and the Atlantic storm tracks are both too weak, but a slight improvement is again found in CMIP5 models with respect to the CMIP3 models, particularly in the Arctic region.

\section{c. CMIP5 cyclone tracking}

The North Atlantic storm track in CMIP5 models is now further investigated using the additional information from the feature-tracking algorithm. Figure 3 shows the mean bias of the CMIP5 models in the same set of diagnostics we presented in Fig. 1. We define a bias as systematic if it is common to the CMIP5 models. This is highlighted by stippling the areas 

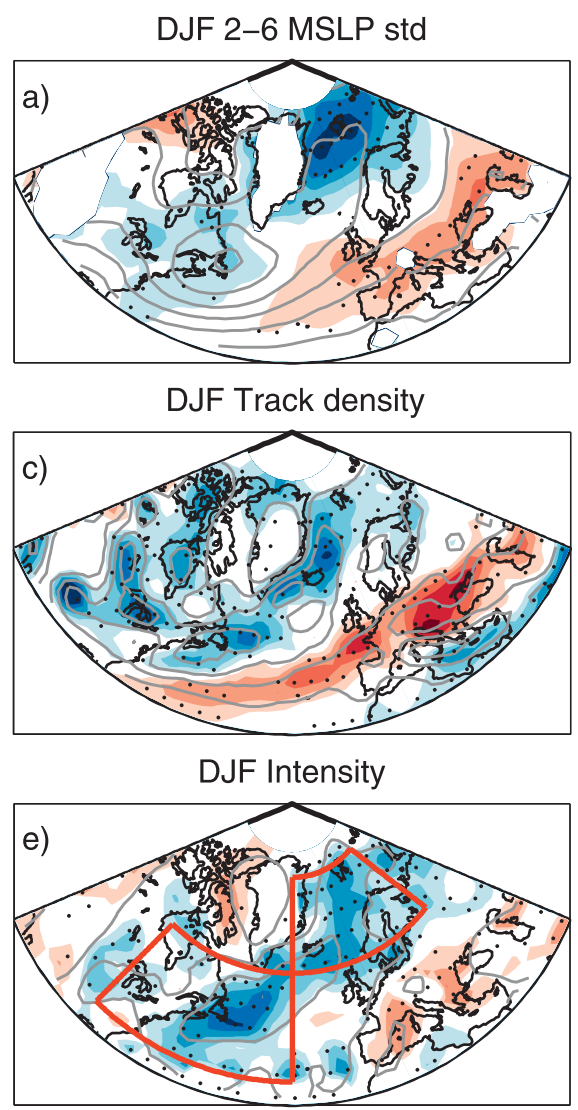

JJA 2-6 MSLP std
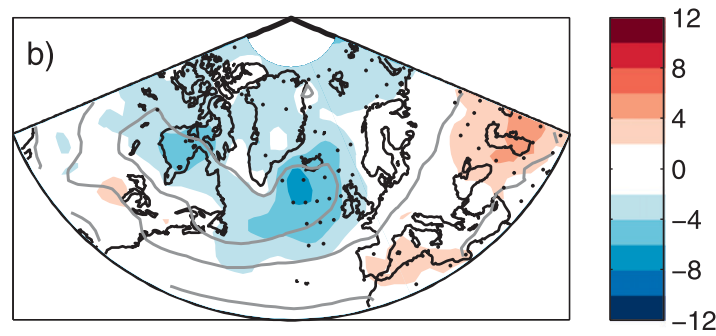

JJA Track density
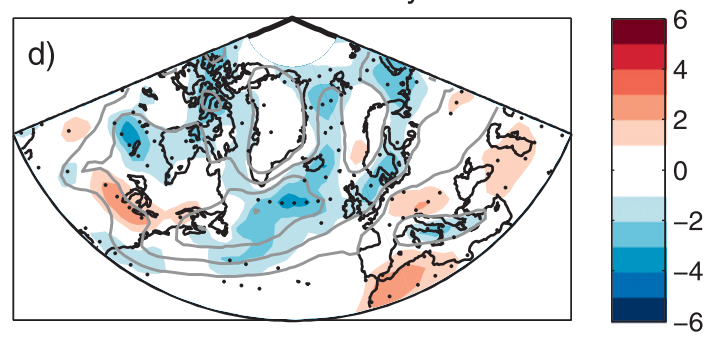

JJA Intensity
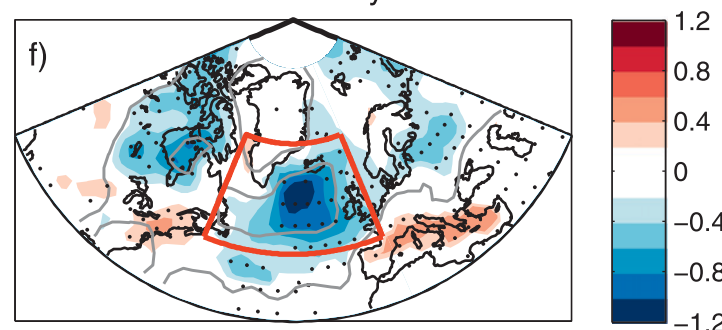

FIG. 3. As in Fig. 1, but for the mean bias (HIST - ERA-Interim) of CMIP5 models. Stippling denotes areas where the bias of at least $80 \%$ of the models has the same sign. ERA-Interim climatology is contoured in gray for (a),(b)

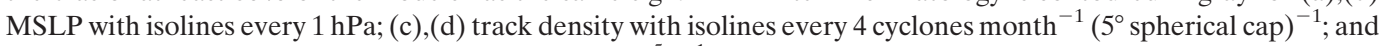
(e),(f) cyclone intensity with isolines every $1.5 \times 10^{-5} \mathrm{~s}^{-1}$. The red lines in (e),(f) define the areas where cyclone intensity is evaluated in section $5 \mathrm{~b}$.

where at least $80 \%$ of the models (18 out of 22$)$ have a bias with the same sign. ${ }^{1}$ The individual model track density biases can be found in the supplementary material.

By comparing Figs. 3a, 3c, and 3e we find that in DJF the positive bias in the 2-6-day MSLP std over central Europe is associated with too many cyclones of slightly overestimated mean intensity. The negative bias in the 2-6-day MSLP std dev over the Norwegian Sea area is instead associated with too few cyclones of weak intensities. Figure $3 \mathrm{e}$ also shows that CMIP5 models tend to underestimate cyclone intensity in the Gulf Stream region, a feature that is less evident in the 2-6-day MSLP std dev (cf. Figs. 3a,e).

\footnotetext{
${ }^{1}$ The probability of this occurring by chance if the model biases had equal probability of being positive or negative is approximately $0.2 \%$.
}

We now explore the ability of CMIP5 models to simulate the North Atlantic storm track in JJA (see Figs. 3b,d,f). The 2-6-day MSLP std dev is underestimated in the northeast Atlantic, where a relative bias of about $15 \%$ with respect to ERA-Interim is found. Consistent with the bias in the 2-6-day MSLP std dev, we find that east Atlantic cyclones are too weak. Track density is also slightly underestimated in the central Atlantic. CMIP5 models have a better representation of the European cyclones in JJA compared with DJF.

The analysis of cyclone tracks has showed that CMIP5 models tend to underestimate the intensity of North Atlantic cyclones, as measured by T42 vorticity at $850 \mathrm{hPa}$, in both DJF and JJA. However, while the spatial distribution of cyclones is roughly captured in JJA, large biases in track density are found in DJF. In particular, despite the improvements that have occurred since CMIP3, the North Atlantic storm track is still too zonal and there are too few cyclones over the Norwegian Sea. 
a)

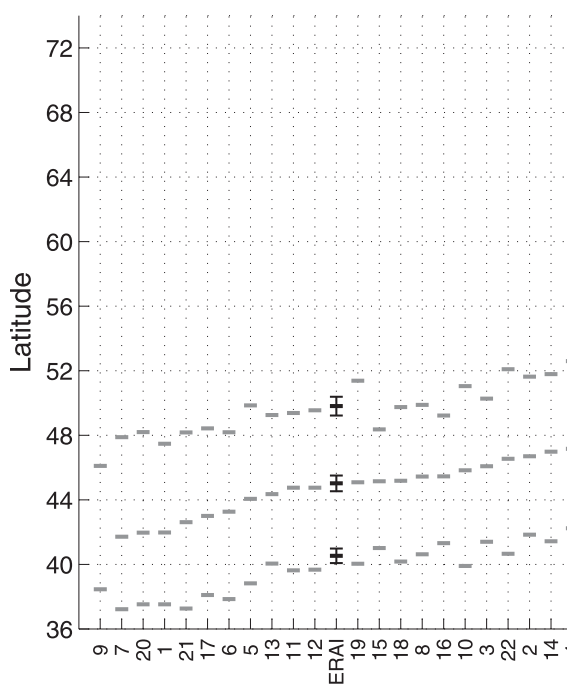

b)

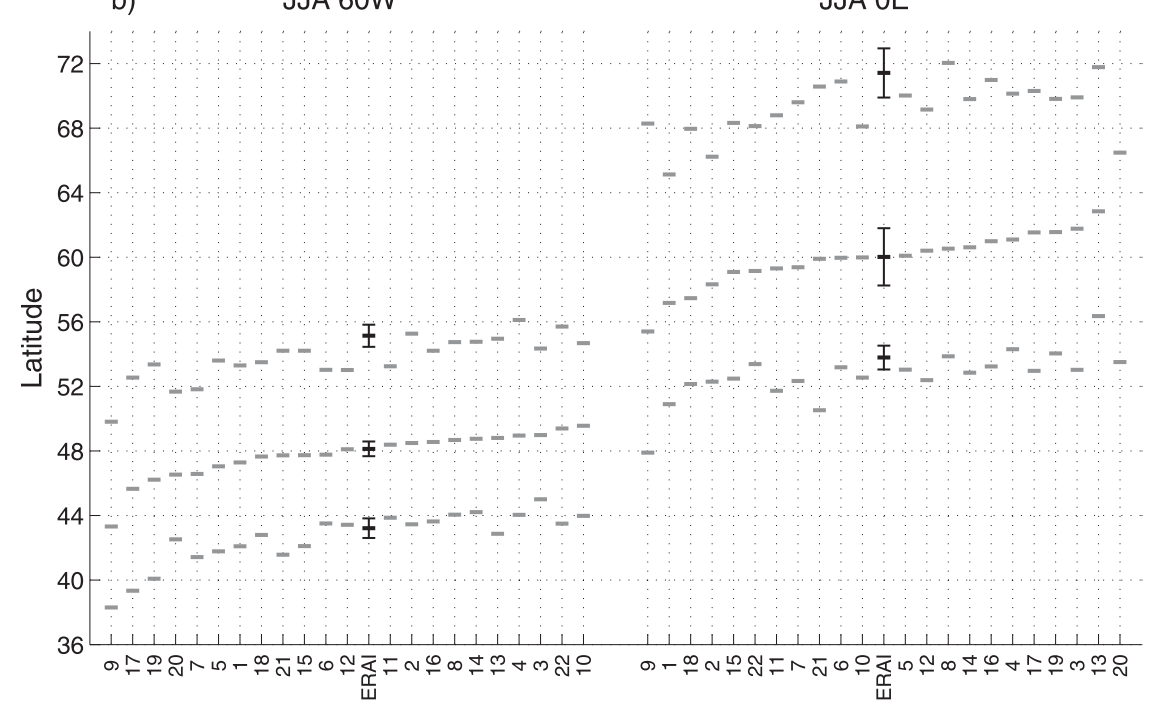

DJF OE

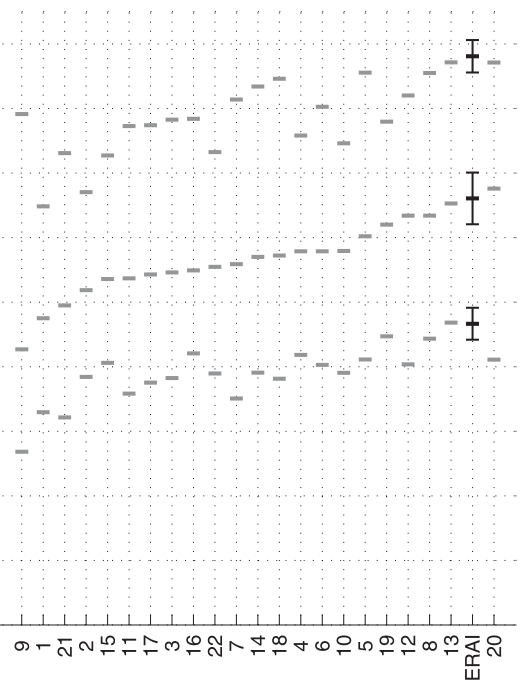

JJA OE

FIG. 4. Latitudinal distribution of cyclone tracks for (a) DJF and (b) JJA at (left) $60^{\circ} \mathrm{W}$ and (right) $0^{\circ}$. Each column corresponds to a CMIP5 model and the three gray dashes indicate the 25th, 50th (median), and 75th percentiles of its latitudinal distribution of tracks. The models can be identified by the labels on the $x$ axis (see Table 1). Values from ERA-Interim are displayed in the column with the black dashes. The $2 \sigma$ confidence intervals are also indicated by error bars for ERA-Interim.

\section{d. CMIP5 intermodel spread in the storm-track position}

To better explore the ability of CMIP5 models to capture the position of the North Atlantic storm track, we now investigate the latitudinal distribution of the North Atlantic cyclones tracks passing at $60^{\circ} \mathrm{W}$ and at $0^{\circ}$. North Atlantic cyclones are defined as those reaching maximum intensity in the area delimited in blue in Figs. 1c and $1 \mathrm{~d}$. The $60^{\circ} \mathrm{W}$ and $0^{\circ}$ meridians have been chosen because they are located on the upstream and the downstream end of the North Atlantic storm track so that its tilt can be determined. For each CMIP5 model and for ERA-Interim, Fig. 4 shows the quartiles of the latitudinal distribution of the tracks passing at $60^{\circ} \mathrm{W}$ and $0^{\circ}$. For ERA-Interim, the $95 \%$ confidence intervals on the quartiles are also shown. The confidence intervals are estimated as 2 times the standard deviation $\left(\sigma_{I}\right)$ of the bootstrap distribution computed by resampling on different years.

In DJF, two different pictures emerge at $60^{\circ} \mathrm{W}$ and at $0^{\circ}$. At $60^{\circ} \mathrm{W}$, CMIP5 models place the storm track either too south or too north with respect to ERA-Interim, 


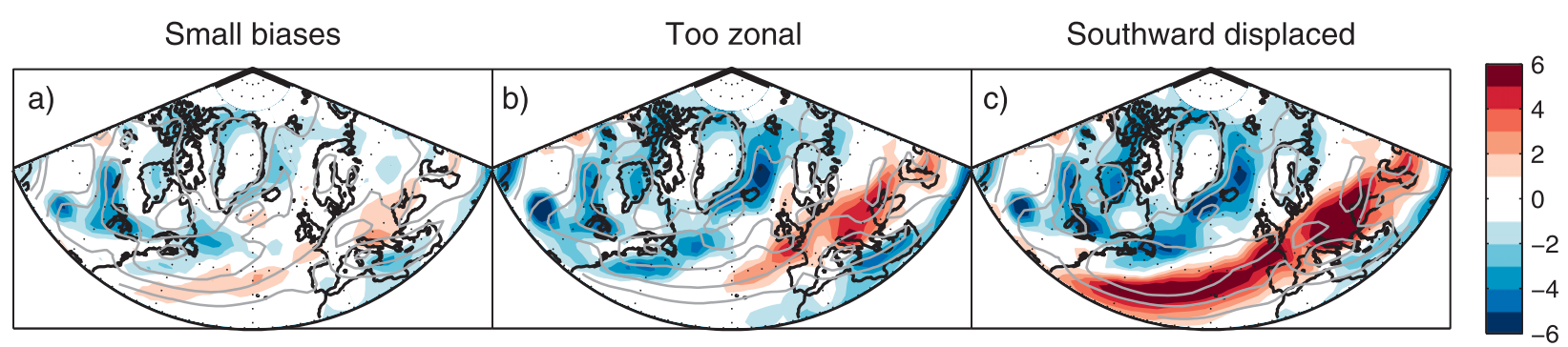

FIG. 5. Mean DJF track density [cyclones month ${ }^{-1}\left(5^{\circ}\right.$ spherical cap) ${ }^{-1}$ ] bias (HIST - ERA-Interim) of the CMIP5 models (shading) separately computed for three groups of similar behavior: (a) the small-bias group, (b) the too-zonal group, and (c) the southwarddisplaced group. The criterion used for defining the groups is given in the text. The group mean climatology is contoured with isolines every 4 cyclones month ${ }^{-1}\left(5^{\circ} \text { spherical cap }\right)^{-1}$.

with the mean model being close to ERA-Interim. The biases are mainly small $\left(\sim 1^{\circ}\right)$ apart from seven models that place the median latitude of tracks about $3^{\circ}-6^{\circ}$ to the south of the observed position. At $0^{\circ}$, the majority of CMIP5 models place the median latitude of tracks too far south, with biases as large as $8^{\circ}$. This again highlights the tendency of CMIP5 models to have a North Atlantic storm track that is too zonal. It is notable, however, that the position of the North Atlantic storm track is well captured by some models.

In JJA, the CMIP5 models tend to much better capture the position of the North Atlantic storm track. For the majority of models, the biases in the median latitude of tracks are small at both $0^{\circ}$ and $60^{\circ} \mathrm{W}$ and the mean model is close to ERA-Interim (see Fig. 4b). It is also of interest to note that models with small biases in DJF might not necessarily perform as well as in JJA and vice versa. For example, while HadGEM2-ES (model 13) and MIROC5 (model 20) show a good distribution of tracks at $0^{\circ}$ during DJF, they have poleward biases in JJA.

The large intermodel spread in the position of the DJF North Atlantic storm track suggests that better insight into the mean track density bias can be gathered by identifying groups of CMIP5 models featuring a similar behavior. An inspection of Fig. 4a suggests that three groups would be adequate for this purpose: models 8,12 , 13 , and 19 have median latitude of tracks consistent with ERA-Interim at both $60^{\circ} \mathrm{W}$ and $0^{\circ}$, which is indicative of small biases in the position of the North Atlantic storm track. Models 1, 5, 6, 7, 9, 17, and 21 underestimate the latitude of cyclones at both $60^{\circ} \mathrm{W}$ and $0^{\circ}$, which is indicative of a southward-displaced storm track. The remaining models, apart from MIROC5, have a poleward shift at $60^{\circ} \mathrm{W}$ and a southward shift at $0^{\circ}$, which is indicative of a too-zonal storm track. In MIROC5 (model 20), the storm track is southward displaced at $60^{\circ} \mathrm{W}$, but it is well positioned at $0^{\circ}$. Motivated by the visual inspection of its track density bias (see supplementary material), we still choose to include MIROC5 in the southward-displaced group, as such bias is dominant across the Atlantic.

To provide quantitative support to the choice of the proposed three groups, we analyze the within-group and between-groups variances of the biases in the storm-track position. The biases are defined by the following vector $\mathbf{d}_{m, g}$ :

$$
\mathbf{d}_{m, g}=\left(\frac{\phi_{m, g}^{60^{\circ} \mathrm{W}}-\phi_{I}^{60^{\circ} \mathrm{W}}}{2 \sigma_{I}^{60^{\circ} \mathrm{W}}}, \frac{\phi_{m, g}^{0^{\circ}}-\phi_{I}^{0^{\circ}}}{2 \sigma_{I}^{0^{\circ}}}\right),
$$

where $\phi_{m, g}$ is the median latitude of tracks of model $m$ in group $g$ at the longitude indicated in the apex and $m=1, \ldots, N_{g}$, with $N_{g}$ being the number of models in group $g$. The term $\phi_{I}$ is the same quantity evaluated for ERA-Interim, and $\sigma_{I}$ is the standard deviation of the median latitude of tracks in ERA-Interim due to sampling uncertainty. The within-group variances $\left[\operatorname{var}\left(\mathbf{d}_{m, \bar{g}}\right)\right.$ for $\bar{g}=1,2,3]$ equal $1.1,3.5$, and $16.3 \mathrm{deg}^{2}$ [ $1 \mathrm{deg}^{2}=$ $\left.(\pi / 180)^{2} \mathrm{sr}\right]$ for the small-bias, too-zonal, and southwarddisplacement groups, respectively. ${ }^{2}$ The between-groups variance is computed as $\operatorname{var}\left(\mathbf{D}_{g}\right)$ with

$$
\mathbf{D}_{g}=\frac{1}{N_{g}} \sum_{m=1}^{N_{g}} \mathbf{d}_{m, g},
$$

and it equals $19.3 \mathrm{deg}^{2}$. As the within-group variances are smaller than the between-groups variance, we judge the three groups to be well separated. The large withingroup variance in the southward-displacement group is due to FGOALS-g2 (model 9), which is affected by a more severe bias. If FGOALS-g2 is removed, $\operatorname{var}\left(\mathbf{d}_{m, 3}\right)$ drops to 5.8.

The group-averaged track density bias is presented for each group in Fig. 5. By comparing Fig. 3c with Figs. 5a-c

\footnotetext{
${ }^{2}$ The variance of the vector is defined as the sum of the variances of its components.
} 

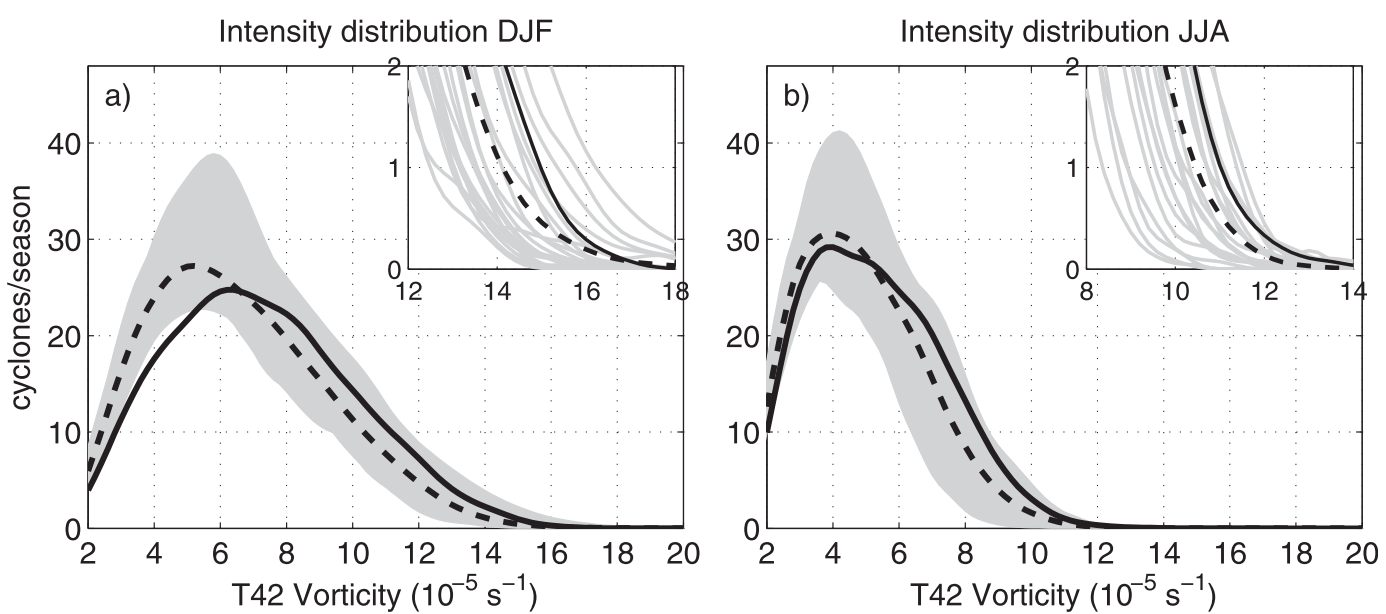

FIG. 6. FD of the maximum along-track North Atlantic cyclone intensity for (a) DJF and (b) JJA. The solid (dashed) line refers to the ERA-Interim (CMIP5 multimodel mean) FD. The gray shading covers from minimum to maximum intermodel spread. The insets show the tail of the distribution, and they also present the FDs of the individual models (gray lines). FD is scaled to cyclones season ${ }^{-1}$ for every $2 \times 10^{-5} \mathrm{~s}^{-1}$ vorticity bin.

we find that the multimodel mean track density bias arises from the superposition of different patterns. As expected, the small-bias group shows smaller track density biases than the multimodel mean. The tripolar pattern in the track density bias over Europe is found in the too-zonal group. The southward-displacement group looks similar to the too-zonal group over Europe, but it also has a southward bias in track density extending over the subtropical Atlantic. The magnitude of the bias in the southward-displacement group is heavily weighted by three CMIP5 models-MIROC-ESM, BCC-CSM1.1, and FGOALS-g2 - that tend to overestimate the number of North Atlantic cyclones (see supplementary material). It is also of interest to note that the small-bias group only includes models of relatively high resolution within CMIP5: GFDL CM3 ( 200 km), HadGEM2-ES $(\sim 170 \mathrm{~km})$, MRI-CGCM3 $(\sim 120 \mathrm{~km})$, and EC-Earth $(\sim 120 \mathrm{~km})$.

\section{Intensity and number of cyclones}

The analyses presented in the previous section suggested that the mean intensity of cyclones is underestimated in CMIP5 models (see Figs. 3e,f). This is now investigated in more detail. The standard life cycle of an extratropical cyclone is characterized by an initial growth, sustained by baroclinic processes, and a subsequent decay, because of viscous dissipation and barotropic conversion (Thorncroft et al. 1993). Given this background, the maximum along-track intensity in T42 vorticity at $850 \mathrm{hPa}$ is a useful measure of the intensity of a cyclone.

The frequency distribution (FD) of the maximum alongtrack intensity of North Atlantic cyclones is computed for each CMIP5 model and for ERA-Interim. North Atlantic cyclones tracks are again defined as those reaching maximum intensity in the area delimited in blue in Figs. 1c and 1d. The results are presented in Fig. 6, where the spread of the FDs of the CMIP5 models is delimited by the gray shading, the multimodel average is indicated by the black dashed line, and ERA-Interim is indicated by the full line.

It is clear from Fig. 6 that CMIP5 models tend to underestimate the number of strong North Atlantic cyclones compared with ERA-Interim. This deficiency particularly affects the extremes. By inspecting the tail of the FD, we find that in DJF the number of cyclones featuring maximum along-track intensities in the range $13-15 \times 10^{-5} \mathrm{~s}^{-1}$ is on average underrepresented by about $50 \%$ by the CMIP5 models. However, the spread in the FDs of CMIP5 models includes ERA-Interim.

To better explore the spread of the CMIP5 models, we now introduce two metrics of North Atlantic stormtrack activity. Specifically, we consider the mean maximum along-track intensity $\mu$ and the total number of cyclones per season $N$. Note that $\mu$ and $N$ are equivalent to the mean and to the integral of the cyclone intensity FD, respectively. The values of $\mu$ and $N$ for each CMIP5 model and for the four modern reanalyses mentioned in section $2 \mathrm{c}$ are presented in Fig. 7 using a joint numberintensity scatterplot. The scatterplot is centered on ERA-Interim. Two ellipses, centered on ERA-Interim, are added to the plot to highlight the area where the relative bias in number and intensity relative to ERA-Interim are within the $10 \%-20 \%$ range. The $2 \sigma$ confidence intervals on $N$ and $\mu$ have been separately computed by bootstrap resampling on different years and they are displayed as error bars on the data points. 

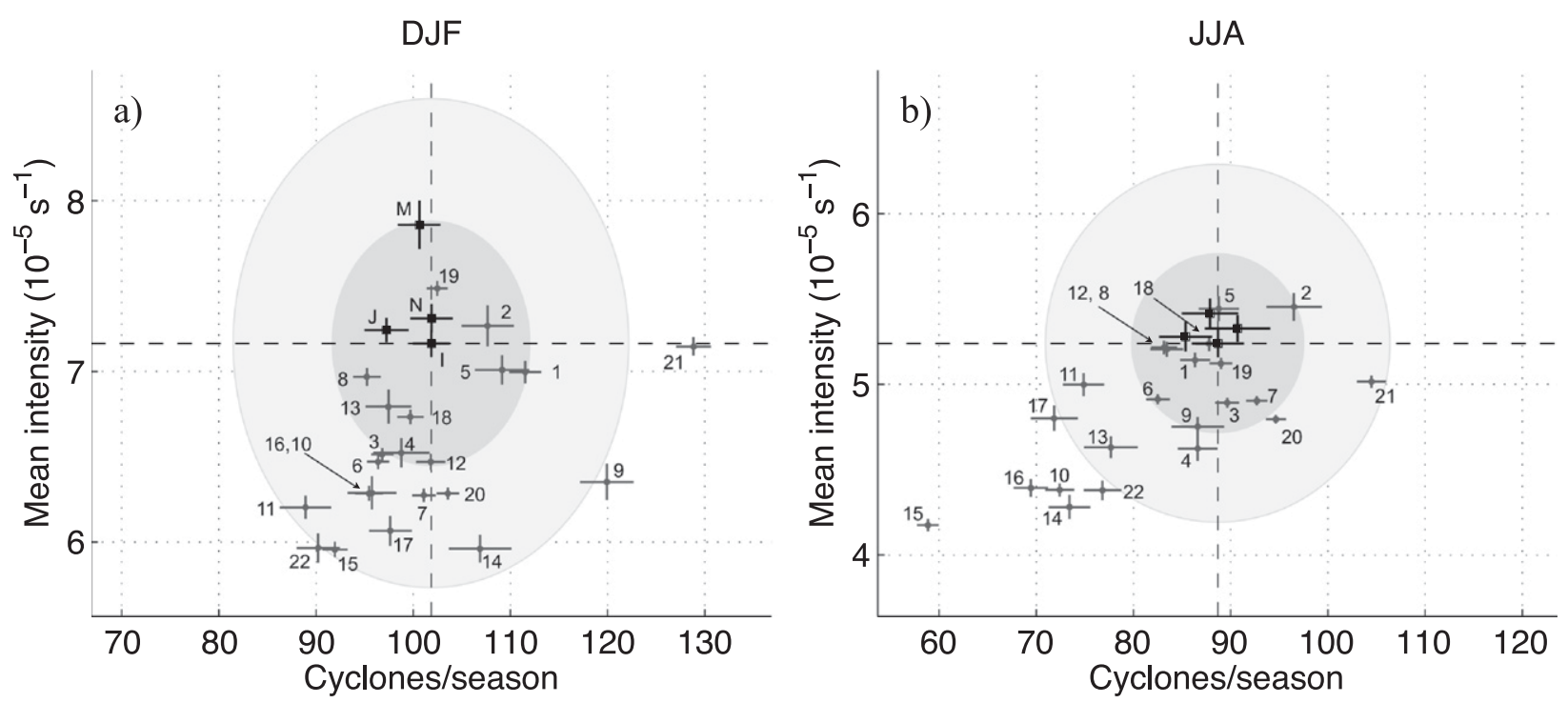

FIG. 7. Scatterplot of mean maximum along-track intensity $\mu\left(10^{-5} \mathrm{~s}^{-1}\right.$; T42 vorticity at $\left.850 \mathrm{hPa}\right)$ against the mean number of North Atlantic cyclones (cyclones season ${ }^{-1}$ ) for (a) DJF and (b) JJA. Gray (black) dots indicate CMIP5 models (reanalyses). The error bars are the $2 \sigma$ confidence intervals. The dark (light) gray ellipses delimit the $10 \%(20 \%)$ relative bias region respect to ERA-Interim. The numbers and letters refer to the model and reanalysis labels given in Tables 1 and 2. Reanalysis labels are not shown for JJA, as they are too close to each other.

In DJF, the error bars of NCEP CFSR, ERA-Interim, and JRA-25 reanalyses overlap, suggesting that the representation of cyclone numbers and intensities is consistent in these three reanalyses. NASA MERRA is consistent with the other reanalyses in $N$ but not in $\mu$, where it is about $10 \%$ higher than in ERA-Interim. The strong intensity of cyclones is a known behavior of NASA MERRA, which is also found in the cyclone wind speed and in the MSLP (Hodges et al. 2011). In JJA, all the reanalyses are in agreement for both $N$ and $\mu$.

In DJF, the CMIP5 models tend to capture the total number of North Atlantic cyclones, but they tend to underestimate their intensity. This conclusion is robust with respect to the observational uncertainty in the intensity of cyclones. However, the spread of the reanalyses is an issue for accurately assessing the performance of the individual models. For instance, MRI-CGCM3 (model 19) has cyclones stronger than ERA-Interim but weaker than NASA MERRA. Some CMIP5 models (e.g., models $5,8,13$, and 18) show small biases with respect to ERAInterim, but intensity biases larger than $10 \%$ relative to NASA MERRA. NorESM1-M (model 22), IPSL-CM5ALR (model 15), and INM-CM4 (model 14) have the largest intensity biases, which are on the order of approximately $20 \%$ with respect to ERA-Interim.

Also in JJA, CMIP5 models tend to underestimate cyclone intensity. However, many models have error bars overlapping with the region defined by the error bars of the reanalyses, which indicates good ability in capturing the basin-integrated number and maximum intensity of North Atlantic cyclones. In contrast, a group of five models underestimates both the number and the intensity of cyclones with biases larger than $20 \%$. These biases are large and they also seem to be positively correlated, with the model featuring the weakest intensityIPSL-CM5A-LR (model 15) - also featuring the smallest number of cyclones. There is a general tendency for CMIP5 models to have intensity biases of similar amplitude in DJF and JJA.

Using the same methodology presented in this section, we also find that North Atlantic cyclones in CMIP5 models tend to be too weak compared with reanalysis in the along-track minimum in full-resolution MSLP and in the along-track maximum in the wind speed at $850 \mathrm{hPa}$ reduced to T42 resolution (not shown). This confirms the results found using vorticity.

Increasing the model resolution seems to have a positive impact on the simulation of North Atlantic cyclones in terms of their number and intensity in DJF. With the exception of the relatively low-resolution (T63) MPI-ESM-LR (model 18), all the models with biases smaller than $10 \%$ relative to ERA-Interim have resolutions higher than N96/T106. Among these highresolution models we also find HadGEM2-ES (model 13), EC-Earth (model 8), and MRI-CGCM3 (model 19), which we previously showed to also have small biases in the representation of the storm-track position and tilt (see section 3d). Moreover IPSL-CM5A-MR (model 
DJF intensity HIST-AMIP

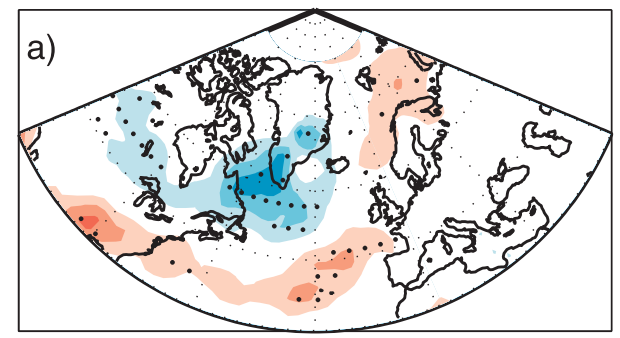

JJA intensity HIST-AMIP

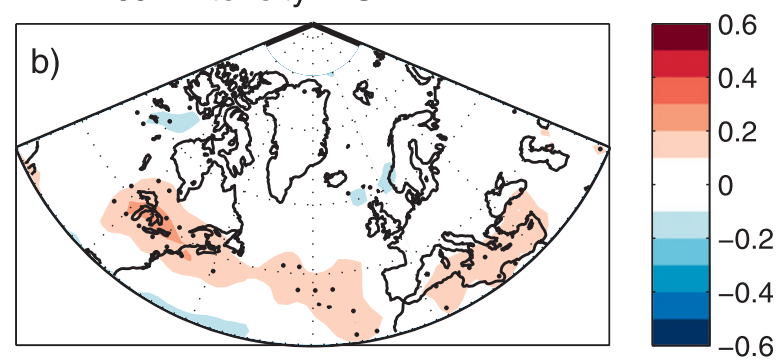

FIG. 8. Mean difference in the intensity $\left(10^{-5} \mathrm{~s}^{-1}\right.$; T42 vorticity at $\left.850 \mathrm{hPa}\right)$ of cyclones between the HIST (coupled) and AMIP (atmosphere only) simulations of 16 CMIP5 models for (a) DJF and (b) JJA. Stippling is applied where the difference has the same sign in at least $80 \%$ of the models.

16) better captures the number and the intensity of cyclones than IPSL-CM5A-LR (model 15), which is its lower-resolution version. An improvement with resolution is also found between BCC-CSM1.1 (model 1) and BCC-CSM1.1m (model 2). However, high resolution does not appear to be a sufficient condition to well capture the North Atlantic cyclones behavior. For example, CCSM4 (model 4), despite its very high resolution, still suffers a too-zonal DJF storm track and moderately weak cyclones in both DJF and JJA. Similar biases in the stormtrack tilt were also found at even higher resolutions in the Athena project simulations (Jung et al. 2012).

The extent that climate models can capture the basinintegrated intensity and number of North Atlantic cyclones in JJA seems to be less resolution dependent. Models with resolution of T42 (BCC-CSM1.1: model 1) and T63 (MPI-ESM-LR: model 18) are also close to ERA-Interim in the $\mu-N$ space. IPSL-CM5B-LR (model 17), which only differs in the parameterizations relative to IPSL-CM5A-LR (model 15), outperforms both IPSLCM5A-LR and its higher-resolution version IPSLCM5A-MR (model 16). Therefore, the behavior of cyclones can be affected by both the resolution and the parameterizations of climate models.

\section{Relationship of biases to the large-scale circulation}

We have found that CMIP5 models tend to underestimate the intensity of North Atlantic cyclones. This bias may be due to either an incorrect representation of dynamical processes on the spatiotemporal scales of cyclones (e.g., baroclinic conversion, diabatic heating, dissipation) or be associated with biases in the largescale processes (e.g., flow-orography interaction, tropical convection, radiative forcing) that determine the environment in which the cyclones grow. A traditional interpretative approach, which is motivated by the importance of baroclinic conversion in sustaining cyclones, is to look for associations between the large-scale atmospheric baroclinicity and the storm-track activity (Hoskins and Valdes 1990; O'Gorman 2010). However, the large-scale baroclinicity is itself influenced by the biases in the vorticity and heat fluxes associated with the cyclone activity. Thus, disentangling the role of cyclonescale and large-scale processes in determining the bias in cyclone behavior can be complicated. Here we attempt to gain some insight into the nature of the biases affecting cyclones in the CMIP5 models by investigating the AMIP simulations, by looking at biases in the jet stream, and by comparing the intensity of North Atlantic and North Pacific cyclones.

\section{a. SST bias}

Systematic biases in the simulated SST affect the surface heat fluxes, the surface baroclinicity, and the tropical convection so that they might have an impact also on the extratropical cyclones (Inatsu and Hoskins 2004; Scaife et al. 2011; Keeley et al. 2012). To test whether this is important in the CMIP5 models, Fig. 8 shows the DJF and JJA multimodel mean difference in mean cyclone intensity between the HIST (coupled) and the AMIP (atmosphere only) simulations. Only the 16 CMIP5 models with data for both the simulations are considered (see Table 1). The mean impact of the SST biases on cyclone intensity is small and it does not project on the pattern of the mean biases of the HIST simulations (cf. Figs. 8a,b with Figs. 3e,f and note the change of scale). The impact on track density is also found to be on average small and only the southwarddisplacement bias is slightly reduced in the AMIP simulations of some models: that is, BCC-CSM1.1, CNRM-CM5, FGOALS-s2, and MIROC5 (not shown). This suggests that the systematic biases in cyclone behavior of CMIP5 models are in general only weakly associated with SST biases and are primarily determined by processes occurring in the atmospheric component of the models. A weak sensitivity of North Atlantic cyclone tracks to SST biases was also found in the Hadley Centre 
DJF U 250hPa

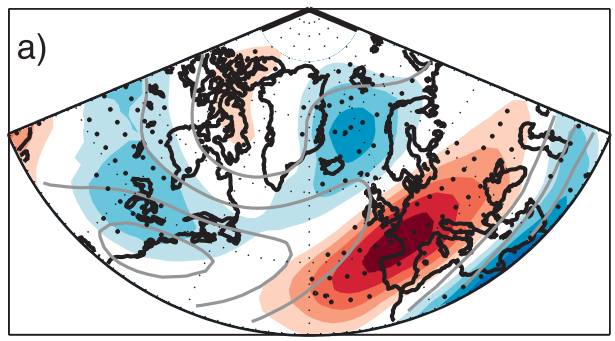

JJA U 250hPa

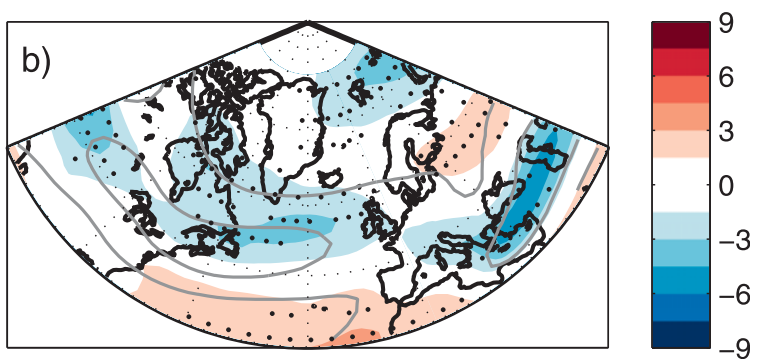

FIG. 9. Mean bias of CMIP5 models (HIST - ERA-Interim) in the mean zonal wind at $250 \mathrm{hPa}$ for (a) DJF and (b) JJA. The mean zonal wind in ERA-Interim is contoured with a contour interval of $10 \mathrm{~m} \mathrm{~s}^{-1}$. Stippling is applied where the bias has the same sign in at least $80 \%$ of the models.

Global Atmosphere Model, version 1 (HadGAM1), by Greeves et al. (2007).

\section{b. Atmospheric mean state}

Figure 9 shows the DJF and JJA multi model mean bias of the CMIP5 models in the zonal wind at $250 \mathrm{hPa}$ (U250). This variable indicates the position of the jet stream and it is related to the meridional temperature gradient through thermal wind balance. Consistent with the eddy-driven nature of the North Atlantic jet (Woollings et al. 2010), good association is found between the track density and U250 biases. In particular, in DJF they both feature a positive bias in Europe and a negative one in the Norwegian Sea, which is characteristic of the too-zonal North Atlantic storm track. In JJA, the mean jet stream is too weak but its location is well captured, which is consistent with the JJA track density bias.

A weak spatial resemblance is found between the bias in U250 and in cyclone intensity. To better explore how they might be associated, we now compute the intermodel correlation between cyclone intensity and U250 area averaged over the regions where the North Atlantic cyclones of CMIP5 models are weakest: the west Atlantic and the Norwegian Sea in DJF and the east Atlantic in JJA. These domains are indicated in Figs. $3 \mathrm{e}$ and $3 \mathrm{f}$ by red boxes and the intermodel correlations are reported in Table 3.

Over the west Atlantic in DJF there is only a weak positive correlation between U250 and cyclone intensity, which is not significant at the $5 \%$ level, as obtained by bootstrap resampling over the different models. However, we find significant correlations in both the east Atlantic in JJA (0.5) and in the Norwegian Sea in DJF (0.7). The positive correlation over the Norwegian Sea suggests that the intensity of cyclones is related to the tilt of the North Atlantic jet stream. Consistent with this view, we have also found that the CMIP5 models with a better representation of the storm-track tilt tend to have number and intensity of cyclones that are close to the reanalyses (cf. Fig. 4a with Fig. 7a). The poor ability of CMIP5 models to capture cyclone intensity in DJF is likely related to the tendency of CMIP5 models to have a too-zonal storm track.

\section{c. Atlantic versus Pacific storm track}

To better understand the nature of the intensity biases, Fig. 10 shows a scatterplot of the mean maximum along-track intensity $\mu$ of North Atlantic and North Pacific cyclones, where North Pacific cyclones are defined as those reaching maximum intensity between $30^{\circ}$ and $70^{\circ} \mathrm{N}$ and between $140^{\circ}$ and $230^{\circ} \mathrm{E}$. The correlation between the intensity of North Atlantic and North Pacific cyclones is 0.83 in DJF and 0.95 in JJA, so that the biases in the intensity of cyclones are apparent across the major $\mathrm{NH}$ storm tracks. Therefore, these results suggest that the intensity biases might in part directly depend on the numerics and parameterizations of the models rather than on the representation of the local large-scale flow via baroclinicity arguments. This interpretation is also suggested in Chang et al. (2013), who found that intensity biases of similar amplitude affect the zonal-averaged storm-track activity of CMIP3 models in the $\mathrm{NH}$ and in the Southern Hemisphere ( $\mathrm{SH})$, while little association was found between the biases in the storm-track activity and in the mean available potential energy of the atmosphere.

\section{Conclusions}

In this paper, we have inspected the ability of CMIP5 models to capture the observed behavior of the North

TABLE 3. Intermodel linear correlation coefficient between the mean cyclone intensity and the zonal wind speed at $250-\mathrm{hPa}$ area averaged in the regions defined in Figs. 3c,d. The 95\% confidence intervals are indicated in brackets.

\begin{tabular}{lll}
\hline \hline Season & \multicolumn{1}{c}{ Region } & \multicolumn{1}{c}{ Correlation } \\
\hline DJF & West Atlantic & $0.2[-0.2 ; 0.5]$ \\
DJF & Norwegian Sea & $0.7[0.2 ; 0.9]$ \\
JJA & East Atlantic & $0.5[0.2 ; 0.8]$ \\
\hline
\end{tabular}


DJF

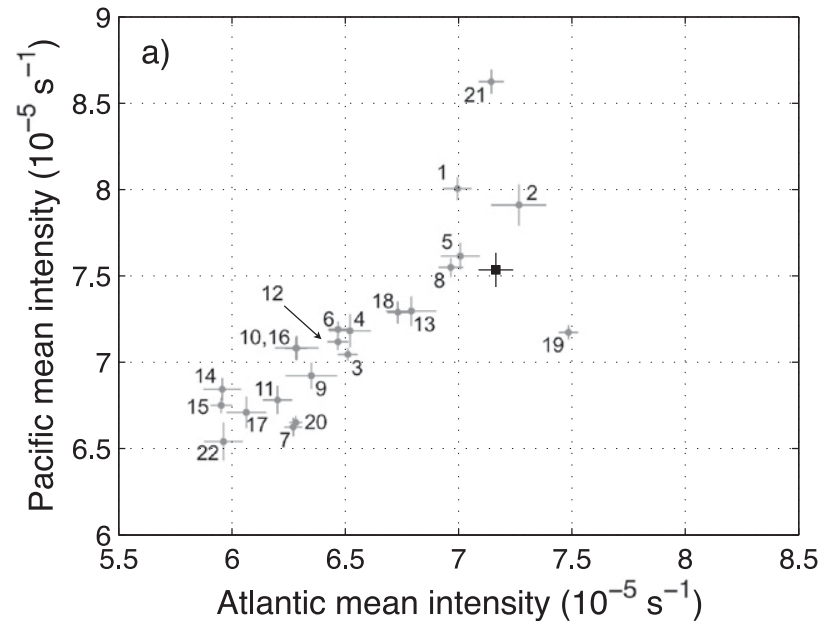

JJA

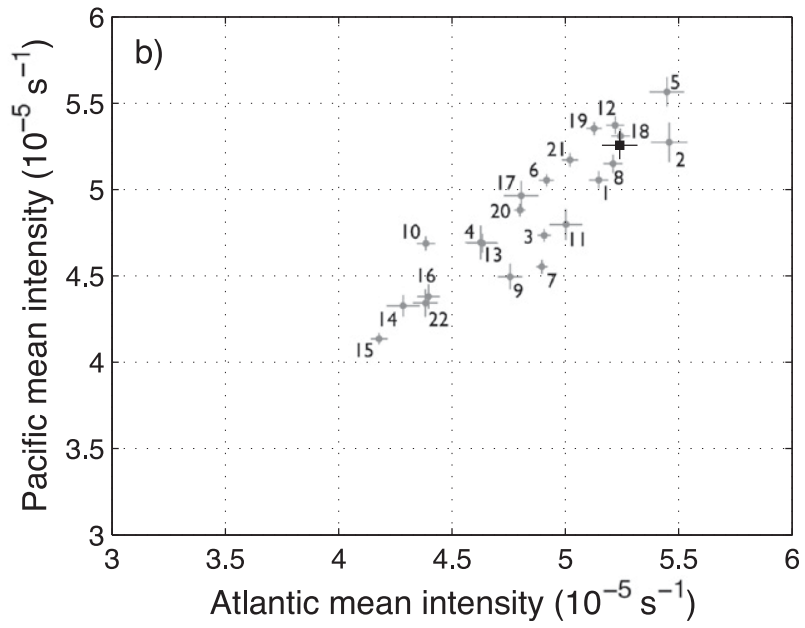

FIG. 10. (a) DJF and (b) JJA scatterplot of the mean maximum along-track intensity $\mu\left(10^{-5} \mathrm{~s}^{-1}\right)$ of North Pacific cyclones vs North Atlantic cyclones in CMIP5 models. CMIP5 models are in gray and ERA-Interim is in black. The error bars are the $2 \sigma$ confidence intervals.

Atlantic extratropical cyclones. The unprecedented availability of CMIP5 high-frequency model output has enabled us to evaluate the number, intensity, and spatial distribution of North Atlantic extratropical cyclones across a wide range of climate models. This study aims to identify common model deficiencies to inform future model development and also to increase the confidence in climate model projections through evaluating the ability of climate models to represent extratropical cyclones.

Cyclones have been identified as relative maxima in the T42 vorticity at $850 \mathrm{hPa}$ and their propagation tracked using an objective feature-tracking algorithm. The intensity of cyclones is measured by the same quantity adopted for the tracking. The number and the intensity of North Atlantic cyclones in the CMIP5 historical (1976-2005) simulations have been evaluated against four recent reanalyses including ERA-Interim (1980-2009).

The main findings of this paper are as follows:

- Relative to CMIP3 models, the CMIP5 models generally show an improved ability to simulate the $\mathrm{NH}$ extratropical storm tracks as measured by the standard deviation of 2-6-day bandpass MSLP. In particular, a substantial improvement is found in the CMIP5 models ability to capture the northeastward tilt and extension of the North Atlantic storm track in the Norwegian Sea in DJF.

- The further information provided by cyclone tracking shows that CMIP5 models are able to capture well the number of North Atlantic extratropical cyclones but their spatial distribution is affected by two biases: 1)
The majority of CMIP5 models still have a too-zonal storm track, so that too many North Atlantic cyclones propagate toward Europe and too few propagate toward the Norwegian Sea area. 2) A group of models also tend to place the storm track too far south in the central Atlantic.

- In JJA, the position and the tilt of the storm track is on average well captured but some CMIP5 models tend to underestimate the total number of North Atlantic extratropical cyclones.

- CMIP5 models tend to underestimate the intensity of cyclones in both DJF and JJA. Such biases seem to be robust with respect to the metric adopted for measuring cyclone intensity, as the minimum MSLP and the maximum wind speed at $850 \mathrm{hPa}$ have also been tested and have given similar results.

- The comparison with AMIP simulations indicates that the biases in cyclone behavior are likely primarily due to the atmospheric component of the models.

- The biases in cyclone intensity can be seen across the NH storm tracks, and they only show weak association with the local intensity of the jet stream over the central Atlantic. This suggests that they might in part directly depend on the numerics and parameterizations of climate models. A larger association with the jet stream is found in the Norwegian Sea area in DJF, where the intensity of cyclones seems to be related to the ability of the models to capture the tilt of North Atlantic jet stream.

- Despite these biases, some CMIP5 models show good ability in simulating the North Atlantic cyclones behavior. In particular, some of the higher-resolution 
models tend to better capture the tilt of the storm track and the intensity of cyclones in DJF.

Results from tracking studies may be sensitive to the characteristics of the adopted tracking algorithm and to the choice of the tracked field (Neu et al. 2012). However, the systematic weakness in the model cyclone intensity and the tendency to place the North Atlantic storm track too far south are also found in the recent CMIP5 study by Chang et al. (2012), where NH and SH extratropical cyclones have been tracked and analyzed using minimum MSLP instead of maximum vorticity. Moreover, the tracking results presented here are also supported by the good consistency with the storm-track biases as measured by the standard deviation of 2-6-day bandpass MSLP.

The intrinsic weakness in the intensity of cyclones, which also affects SH cyclones in Chang et al. (2012), suggests that some cyclone-scale processes, such as baroclinic conversion, diabatic heating, or dissipation, might not be correctly captured. For example, Boer and Lambert (2008) found that CMIP3 models tend to overestimate the dissipation of eddy kinetic energy, and Chang et al. (2013) suggests that the intensity of dissipation might be important in determining the CMIP3 model biases in stormtrack activity. If this problem were also to apply in CMIP5, it could contribute to the observed systematic weakness in cyclone intensity. This highlights the importance of introducing diagnostics able to quantify the energetics of cyclones (Laîné et al. 2009).

We find that only some of the CMIP5 models with relatively high atmospheric resolution have a good representation of both the intensity of North Atlantic cyclones and of the tilt of the North Atlantic storm track in DJF. This is consistent with the marked improvement in the spatial distribution and intensity of wintertime North Atlantic cyclones in HadGAM1 by increasing resolution from N48 $(\sim 340 \mathrm{~km})$ to N96 $(\sim 170 \mathrm{~km})$ (Greeves et al. 2007). It is also consistent with the improvement in the simulation of the tilt of the North Atlantic storm track since CMIP3, which included substantially coarserresolution models than CMIP5 (Randall et al. 2007). In JJA, a good simulation of North Atlantic cyclone number and intensity is found in both some low- and high-resolution models. Care is required when inferring the impact of one specific feature of climate models by exploring a multimodel ensemble of this size. However, these results suggest that high resolution (about T106 or N96) might be necessary for a good simulation of the North Atlantic storm track in DJF, while lower resolutions might be already adequate in JJA. The larger sensitivity to resolution in DJF might come from the importance of high resolution for better determining the tilt of the storm track via flow-orography interaction or via the generation and maintenance of blocking highs (Nakamura and Wallace 1993; Woollings et al. 2010; Jung et al. 2012). However, we also have to consider that the intrinsic weakness in cyclone intensity, via the bias in the associated vorticity and momentum fluxes, might themselves contribute to the systematic biases in the mean state (Hoskins et al. 1983) or in the generation of blocks (Nakamura and Wallace 1993). Further research is needed to address these issues.

The tendency of CMIP5 models to have weak cyclones and a too-zonal North Atlantic storm track in DJF is certainly a source of concern for interpreting their future projections. However, the presence of CMIP5 models with good ability in capturing the behavior of North Atlantic cyclones implies that the sensitivity of the climate change responses to the model biases may be evaluated. If the responses were independent from the biases, the confidence in the mean projection of CMIP5 models would be increased. Otherwise, if a relation between the future response and the present-day bias could be identified, it would provide an emerging constraint for better calibrating the multimodel projection (e.g., Bracegirdle and Stephenson 2012). An assessment of the North Atlantic cyclones responses to climate change in CMIP5 models is presented in Zappa et al. (2013), where the sensitivity to the model biases is also discussed.

Acknowledgments. The authors thank D. B. Stephenson for the insightful discussions and two anonymous reviewers, whose comments helped to improve the paper. We acknowledge the World Climate Research Programme's Working Group on Coupled Modelling, which is responsible for CMIP, and we thank the climate modeling groups (listed in Table 1 of this paper) for producing and making available their model output. For CMIP, the U.S. Department of Energy's Program for Climate Model Diagnosis and Intercomparison provides coordinating support and led development of software infrastructure in partnership with the Global Organisation for Earth System Science Portals. This study is part of the Testing and Evaluating Model Simulations of European Storms (TEMPEST) project, which is funded by NERC.

\section{APPENDIX}

\section{CMIP3 Models}

The years 1961-2000 from the CMIP3 twentiethcentury (20C3M) simulations of the following 19 CMIP3 models have been considered (other model expansions can be found in Table 1): Bjerknes Centre for Climate Research Bergen Climate Model, version 2.0 (BCCRBCM2.0); Canadian Centre for Climate Modelling and 
Analysis (CCCma) Coupled General Circulation Model, version 3.1 (CGCM3.1) T47 (5); CGCM3.1 T63; CNRM CGCM, version 3 (CNRM-CM3); CSIRO Mark version 3.0 (CSIRO Mk3.0) (2); CSIRO Mark version 3.5 (CSIRO Mk3.5) (3); ECHAM5/MPI-OM (2); ECHAM and the global Hamburg Ocean Primitive Equation (ECHO-G); GFDL Climate Model, version 2.0 (GFDL CM2.0); GFDL Climate Model, version 2.1 (GFDL CM2.1); Goddard Institute for Space Studies AtmosphereOcean Model (GISS-AOM); GISS Model E-R (GISSER); Istituto Nazionale di Geofisica e Vulcanologia Scale Interaction Experiment (SINTEX)-G (INGV-SXG); INM Coupled Model, version 3.0 (INM-CM3.0); IPSL Coupled Model, version 4 (IPSL-CM4) (2); MIROC 3.2, high-resolution version [MIROC3.2(hires)]; MIROC 3.2, medium-resolution version [MIROC3.2(medres)]; MRI CGCM, version 2.3.2 (MRI-CGCM2.3.2); and CCSM, version 3 (CCSM3). Only one ensemble is used for each model unless differently specified in parenthesis after the model. See Randall et al. (2007) for a summary of the model characteristics.

\section{REFERENCES}

Bengtsson, L., K. I. Hodges, and E. Roeckner, 2006: Storm tracks and climate change. J. Climate, 19, 3518-3543.

,$- \ldots$, and N. Keenlyside, 2009: Will extratropical storms intensify in a warmer climate? J. Climate, 22, 2276-2301.

Blackmon, M., 1976: A climatological spectral study of the $500 \mathrm{mb}$ geopotential height of the Northern Hemisphere. J. Atmos. Sci., 33, 1607-1623.

Blender, R., and M. Schubert, 2000: Cyclone tracking in different spatial and temporal resolutions. Mon. Wea. Rev., 128, 377384.

Boer, G., and S. Lambert, 2008: The energy cycle in atmospheric models. Climate Dyn., 30, 371-390.

Bracegirdle, T. J., and D. B. Stephenson, 2012: Higher precision estimates of regional polar warming by ensemble regression of climate model projections. Climate Dyn., 39, 2805-2821, doi:10.1007/s00382-012-1330-3.

Brayshaw, D. J., B. Hoskins, and M. Blackburn, 2009: The basic ingredients of the North Atlantic storm track. Part I: Land-sea contrast and orography. J. Atmos. Sci., 66, 2539-2558.

Catto, J., L. Shaffrey, and K. I. Hodges, 2010: Can climate models capture the structure of extratropical cyclones? J. Climate, 23, $1621-1635$.

,$- \ldots$, and $—, 2011$ : Northern Hemisphere extratropical cyclones in a warming climate in the HiGEM high-resolution climate model. J. Climate, 24, 5336-5352.

Chang, E. K. M., 2009: Are band-pass variance statistics useful measures of storm track activity? Re-examining storm track variability associated with the NAO using multiple storm track measures. Climate Dyn., 33, 277-296.

—, Y. Guo, and X. Xia, 2012: CMIP5 multi-model ensemble projection of storm track change under global warming. J. Geophys. Res., 117, D23118, doi:10.1029/2012JD018578.

,,--- , and M. Zheng, 2013: Storm track activity in IPCC AR4/CMIP3 model simulations. J. Climate, 26, 246-260.
Duchon, C. E., 1979: Lanczos filtering in one and two dimensions. J. Appl. Meteor., 18, 1016-1022.

Fink, A., T. Brücher, V. Ermert, A. Krüger, and J. G. Pinto, 2009: The European storm Kyrill in January 2007: Synoptic evolution, meteorological impacts and some considerations with respect to climate change. Nat. Hazards Earth Syst. Sci., 9, 405-423.

Greeves, C., V. Pope, R. Stratton, and G. M. Martin, 2007: Representation of Northern Hemisphere winter storm tracks in climate models. Climate Dyn., 28, 683-702.

Hodges, K. I., 1994: A general method for tracking analysis and its application to meteorological data. Mon. Wea. Rev., 122, 2573-2586. 1995: Feature tracking on the unit sphere. Mon. Wea. Rev., 123, 3458-3465.

, 1996: Spherical nonparametric estimators applied to the UGAMP model integration for AMIP. Mon. Wea. Rev., 124, 2914-2932.

, 1999: Adaptive constraints for feature tracking. Mon. Wea. Rev., 127, 1362-1373.

, R. W. Lee, and L. Bengtsson, 2011: A comparison of extratropical cyclones in recent reanalyses ERA-Interim, NASA MERRA, NCEP CFSR, and JRA-25. J. Climate, 24, 48884906.

Hoskins, B., and P. Valdes, 1990: On the existence of storm-tracks. J. Atmos. Sci., 47, 1854-1864.

— Hemisphere winter storm tracks. J. Atmos. Sci., 59, 1041-1061.

—, I. James, and G. White, 1983: The shape, propagation and mean-flow interaction of large-scale weather systems. J. Atmos. Sci., 40, 1595-1612.

Inatsu, M., and B. Hoskins, 2004: The zonal asymmetry of the Southern Hemisphere winter storm track. J. Climate, 17, 4882-4892.

Jung, T., and Coauthors, 2012: High-resolution global climate simulations with the ECMWF model in Project Athena: Experimental design, model climate and seasonal forecast skill. J. Climate, 25, 3155-3172.

Keeley, S. P. E., R. T. Sutton, and L. C. Shaffrey, 2012: The impact of North Atlantic sea surface temperature errors on the simulation of North Atlantic European region climate. Quart. J. Roy. Meteor. Soc., 138, 1774-1783, doi:10.1002/qj.1912.

Kidston, J., and E. P. Gerber, 2010: Intermodel variability of the poleward shift of the austral jet stream in the CMIP3 integrations linked to biases in 20th century climatology. Geophys. Res. Lett., 37, L09708, doi:10.1029/2010GL042873.

Laîné, A., M. Kageyama, D. Salas-Mélia, G. Ramstein, S. Planton, S. Denvil, and S. Tyteca, 2009: An energetics study of wintertime Northern Hemisphere storm tracks under $4 \times \mathrm{CO}_{2}$ conditions in two ocean-atmosphere coupled models. J. Climate, 22, 819-839.

Lamb, H., 1991: Historic Storms of the North Sea, British Isles and Northwest Europe. Cambridge University Press, 204 pp.

Lambert, S. J., and J. C. Fyfe, 2006: Changes in winter cyclone frequencies and strengths simulated in enhanced greenhouse warming experiments: Results from the models participating in the IPCC diagnostic exercise. Climate Dyn., 26, 713-728.

, J. Sheng, and J. Boyle, 2002: Winter cyclone frequencies in thirteen models participating in the Atmospheric Model Intercomparison Project (AMIP1). Climate Dyn., 19, 1-16.

Leckebusch, G. C., and U. Ulbrich, 2004: On the relationship between cyclones and extreme windstorm events over Europe under climate change. Global Planet. Change, 44, 181-193.

Lucarini, V., S. Calmanti, A. Dell'Aquila, P. Ruti, and A. Speranza, 2007: Intercomparison of the Northern Hemisphere winter 
mid-latitude atmospheric variability of the IPCC models. Climate Dyn., 28, 829-848.

Nakamura, H., and J. Wallace, 1993: Synoptic behavior of baroclinic eddies during the blocking onset. Mon. Wea. Rev., 121, 1892-1903.

Neu, U., and Coauthors, 2012: IMILAST_A community effort to intercompare extratropical cyclone detection and tracking algorithms: Assessing method-related uncertainties. Bull. Amer. Meteor. Soc., 94, 529-547.

O'Gorman, P. A., 2010: Understanding the varied response of the extratropical storm tracks to climate change. Proc. Natl. Acad. Sci. USA, 107, 19176-19180.

Onogi, K., and Coauthors, 2007: The JRA-25 Reanalysis. J. Meteor. Soc. Japan, 85, 369-432.

Peixoto, J., and A. Oort, 1992: Physics of Climate. American Institute of Physics, 520 pp.

Pinto, J., E. Fröhlich, G. Leckebusch, and U. Ulbrich, 2007a: Changing European storm loss potentials under modified climate conditions according to ensemble simulations of the ECHAM5/ MPI-OM1 GCM. Nat. Hazards Earth Syst. Sci., 7, 165-175.

- , U. Ulbrich, G. Leckebusch, T. Spangehl, M. Reyers, and S. Zacharias, 2007b: Changes in storm track and cyclone activity in three SRES ensemble experiments with the ECHAM5/ MPI-OM1 GCM. Climate Dyn., 29, 195-210.

Raible, C., P. Della-Marta, C. Schwierz, H. Wernli, and R. Blender, 2008: Northern Hemisphere extratropical cyclones: A comparison of detection and tracking methods and different reanalyses. Mon. Wea. Rev., 136, 880-897.

Randall, D., and Coauthors, 2007: Climate models and their evaluation. Climate Change 2007: The Physical Science Basis, S. Solomon et al., Eds., Cambridge University Press, 589-662.

Rienecker, M. M., and Coauthors, 2011: MERRA: NASA's Modern-Era Retrospective Analysis for Research and Applications. J. Climate, 24, 3624-3648.

Saha, S., and Coauthors, 2010: The NCEP Climate Forecast System Reanalysis. Bull. Amer. Meteor. Soc., 91, 1015-1057.
Scaife, A., and Coauthors, 2011: Improved Atlantic winter blocking in a climate model. Geophys. Res. Lett., 38, L23703, doi:10.1029/2011GL049573.

Simmons, A., S. Uppala, D. Dee, and S. Kobayashi, 2007: ERAInterim: New ECMWF reanalysis products from 1989 onwards. ECMWF Newsletter, No. 100, ECMWF, Reading, United Kingdom, 25-35.

Sinclair, M., and I. Watterson, 1999: Objective assessment of extratropical weather systems in simulated climates. J. Climate, 12, 3467-3485.

Taylor, K., R. Stouffer, and G. Meehl, 2012: An overview of CMIP5 and the experiment design. Bull. Amer. Meteor. Soc., 93, 485-498.

Thorncroft, C., B. Hoskins, and M. McIntyre, 1993: Two paradigms of baroclinicwave life-cycle behaviour. Quart. J. Roy. Meteor. Soc., 119, 17-55.

Ulbrich, U., J. G. Pinto, H. Kupfer, G. C. Leckebusch, T. Spangehl, and M. Reyers, 2008: Changing Northern Hemisphere storm tracks in an ensemble of IPCC climate change simulations. J. Climate, 21, 1669-1679.

_ G. Leckebusch, and J. Pinto, 2009: Extra-tropical cyclones in the present and future climate: A review. Theor. Appl. Climatol., 96, 117-131.

Wallace, J., G. Lim, and M. Blackmon, 1988: Relationship between cyclone tracks, anticyclone tracks and baroclinic waveguides. J. Atmos. Sci., 45, 439-462.

Wang, X., V. Swail, and F. Zwiers, 2006: Climatology and changes of extratropical cyclone activity: Comparison of ERA-40 with NCEP-NCAR reanalysis for 1958-2001. J. Climate, 19, 31453166.

Woollings, T., A. Hannachi, and B. Hoskins, 2010: Variability of the North Atlantic eddy-driven jet stream. Quart. J. Roy. Meteor. Soc., 136, 856-868.

Zappa, G., L. C. Shaffrey, K. I. Hodges, P. Sansom, and D. B. Stephenson, 2013: A multimodel assessment of future projections of North Atlantic and European cyclones in the CMIP5 climate models. J. Climate, in press. 